\title{
Molecular composition of the human primary visual cortex profiled by multimodal mass spectrometry imaging
}

\author{
Estibaliz González de San Román ${ }^{1,2} \cdot$ Hans-Jürgen Bidmon ${ }^{2} \cdot$ Milena Malisic $^{1,2} \cdot$ Iuliana Susnea $^{1} \cdot$ Astrid Küppers $^{1}$. \\ Rene Hübbers $^{2,3} \cdot$ Andreas Wree $^{4} \cdot$ Volker Nischwitz $^{1} \cdot$ Katrin Amunts $^{2,3} \cdot$ Pitter F. Huesgen ${ }^{1}$
}

Received: 22 June 2017 / Accepted: 29 March 2018 / Published online: 10 April 2018

(c) The Author(s) 2018

\begin{abstract}
The primary visual cortex (area V1) is an extensively studied part of the cerebral cortex with well-characterized connectivity, cellular and molecular architecture and functions (for recent reviews see Amunts and Zilles, Neuron 88:1086-1107, 2015; Casagrande and $\mathrm{Xu}$, Parallel visual pathways: a comparative perspective. The visual neurosciences, MIT Press, Cambridge, pp 494-506, 2004). In humans, V1 is defined by heavily myelinated fibers arriving from the radiatio optica that form the Gennari stripe in cortical layer IV, which is further subdivided into laminae IVa, IVb, IVc $\alpha$ and IVc $\beta$. Due to this unique laminar pattern, V1 represents an excellent region to test whether multimodal mass spectrometric imaging could reveal novel biomolecular markers for a functionally relevant parcellation of the human cerebral cortex. Here we analyzed histological sections of three post-mortem brains with matrix-assisted laser desorption/ionization mass spectrometry imaging and laser ablation inductively coupled plasma mass spectrometry imaging to investigate the distribution of lipids, proteins and metals in human V1. We identified 71 peptides of 13 different proteins by in situ tandem mass spectrometry, of which 5 proteins show a differential laminar distribution pattern revealing the border between V1 and V2. High-accuracy mass measurements identified 123 lipid species, including glycerolipids, glycerophospholipids and sphingolipids, of which at least 20 showed differential distribution within V1 and V2. Specific lipids labeled not only myelinated layer IVb, but also IVa and especially IVc in a layer-specific manner, but also and clearly separated V1 from V2. Elemental imaging further showed a specific accumulation of copper in layer IV. In conclusion, multimodal mass spectrometry imaging identified novel biomolecular and elemental markers with specific laminar and inter-areal differences. We conclude that mass spectrometry imaging provides a promising new approach toward multimodal, molecule-based cortical parcellation.
\end{abstract}

Keywords Human brain · Peptides · Lipids $\cdot$ Elements $\cdot$ Mass spectrometry imaging $\cdot$ Primary visual cortex $\cdot$ MALDI mass spectrometry imaging $\cdot$ Laser ablation inductively coupled plasma mass spectrometry imaging

Estibaliz González de San Román and Hans-Jürgen Bidmon
contributed equally to the study.

Electronic supplementary material The online version of this article (https://doi.org/10.1007/s00429-018-1660-y) contains supplementary material, which is available to authorized users.

Katrin Amunts

k.amunts@fz-juelich.de

Pitter F. Huesgen

p.huesgen@fz-juelich.de

1 Central Institute of Engineering, Electronics and Analytics, ZEA-3, Forschungszentrum Jülich, Jülich, Germany

2 Cécile and Oskar Vogt Institute of Brain Research, Medical Faculty, Heinrich Heine University Düsseldorf, Düsseldorf, Germany

\section{Abbreviations}

V1 Primary visual cortex

V2 Secondary visual cortex

MALDI-MSI Matrix-assisted laser desorption/ionization mass spectrometry imaging

3 Institute of Neuroscience and Medicine, INM-1, Forschungszentrum Jülich, Jülich, Germany

4 Institute of Anatomy, Rostock University Medical Center, Rostock, Germany 


$\begin{array}{ll}\text { LA-ICP-MS } & \begin{array}{l}\text { Laser ablation inductively coupled plasma } \\ \text { mass spectrometry }\end{array} \\ \text { GM } & \text { Gray matter } \\ \text { WM } & \text { White matter } \\ \text { DHB } & \text { 2, 5-dihydroxybenzoic acid } \\ \text { TFA } & \text { Trifluoroacetic acid } \\ \text { Cer } & \text { Ceramide } \\ \text { DG } & \text { Diglyceride } \\ \text { GlcCer } & \text { Glucosylceramide } \\ \text { LPC } & \text { Lysophosphatidylcholine } \\ \text { PC } & \text { Phosphatidylcholine } \\ \text { PA } & \text { Phosphatidic acid } \\ \text { PE } & \text { Phosphatidylethanolamine } \\ \text { PS } & \text { Phosphatidylserine } \\ \text { SM } & \text { Sphingomyelin } \\ \text { PI-Cer } & \text { Ceramide phosphoinositol }\end{array}$

\section{Introduction}

Delineation of distinct functional regions of the brain is a prerequisite for a deeper understanding of brain function under both normal and pathological conditions. Traditionally, the functional parcellation of the human cerebral cortex has been addressed by cytoarchitectonic and myeloarchitectonic studies (Brodmann 1909; Von Economo and Koskinas 1925; Hubel and Wiesel 1977; Van Essen et al. 1992). More recent approaches have introduced observer-independent mapping techniques which significantly increased the number of cortical areas compared to Brodmann's map and provided maps of areas in 3D-space (Zilles and Amunts 2010; Amunts and Zilles 2015). Such maps allowed the interpretation of in vivo studies employing, for example, functional magnetic resonance imaging (fMRI) with respect to the topography of activated networks and thus provide the basis for analyzing structure-function correlations (e.g. Rosenke et al. 2017; Eickhoff et al. 2005). In addition, human brain mapping has been greatly facilitated by specific molecular approaches including quantitative receptor autoradiography (Zilles and Amunts 2009). However, all commonly used cytochemical approaches to cortical parcellation require the selection of specific, previously known and often wellcharacterized molecules such as (radio-) labeled neurotransmitter receptor ligands, or antibodies towards peptides and proteins.

Over the past two decades, a variety of mass spectrometry imaging (MSI) techniques have been developed that enable simultaneous mapping of multiple proteins, peptides, lipids or elements and hence definition of molecular anatomy in a highly explorative manner (Chughtai and Heeren 2010). In principle, these techniques open new avenues for a detailed molecular parcellation of the brain. Matrix-assisted laser desorption/ionization mass spectrometry imaging
(MALDI-MSI) is arguably the most versatile method among these, as it allows label-free detection of endogenous biomolecules including proteins and lipids and/or selected molecules of interest as, for example, drug compounds or their metabolites in any given tissue (Norris and Caprioli 2013; Shariatgorji et al. 2014). MALDI-MSI has been widely used to determine molecular changes associated with cancer and other pathologies in human tissue and animal models of human disease (Matsumoto et al. 2011; Dekker et al. 2015; Schubert et al. 2016; Martinez-Gardeazabal et al. 2017). In neurosciences, several studies used this technique to characterize the distribution of biomolecules such as lipids in the healthy (Veloso et al. 2011a, b; Manuel et al. 2015) and diseased human brain (Yuki et al. 2011). For example, studies of the human cerebral cortex described differences for the lipid distribution among gray and white matter (Veloso et al. 2011a,b; Lazar et al. 2013), but did not show a detailed cortical parcellation. Another study employed high-resolution imaging of lipids and proteins in the human optical nerve, and demonstrated region- and cell layer-specific distribution (Anderson et al. 2015).

Complementary to MALDI-MSI, laser ablation inductively coupled plasma mass spectrometry imaging (LA-ICPMSI) allows measurement of elemental concentrations in a tissue in a spatially resolved manner. Similar to MALDIMSI, LA-ICP-MSI has been used to study the distribution of elements in various animal models and human tissue samples (Becker et al. 2014; Susnea and Weiskirchen 2016) and to characterize changes in cerebral metal accumulation associated with disease, as, for example, in Wilson's disease (Boaru et al. 2014).

Here we tested whether explorative techniques such as LA-ICP-MSI and MALDI-MSI could provide additional information about the presence of elements, proteins and lipids in the human brain. The primary visual cortex (V1, Area striata, or Brodmann area 17) is an anatomically wellcharacterized cortical area with a unique laminar pattern and was, therefore, chosen as a challenging test case. Our aim was to provide a proof-of-concept for MALDI-MSI of lipids and proteins and elemental imaging by LA-ICP-MSI as unbiased approaches to reveal regional and laminar characteristics of $\mathrm{V} 1$ at a resolution of $100 \mu \mathrm{m}$ as afforded by standard commercial instruments.

\section{Materials and methods}

\section{Chemicals and reagents}

All chemicals and reagents were obtained in the highest commercially available quality. 2,5-dihydroxybenzoic acid (DHB), trifluoroacetic acid (TFA) and ammonium hydrogen carbonate were obtained from Sigma-Aldrich (Steinheim, 
Germany), trypsin and methanol were purchased from Thermo scientific (Dreieich, Germany) and methanol (LC-MS grade) was purchased from Thermo Fisher Scientific (Geel, Belgium), Water (LC-MS grade) was purchased from VWR (Leuven, Belgium).

\section{Human brain specimen}

Post-mortem human brain samples were obtained at autopsy from the body donor program of the Center of Anatomy and Brain Research, Heinrich-Heine-University of Düsseldorf, Germany and the Institute of Anatomy of the University of Rostock, Germany (Table 1); the use of the brain samples had been approved by ethics committee of the Faculty of Medicine at the Heinrich-Heine-University of Düsseldorf under the study-No. 4863 . Brain samples were stored at $-80^{\circ} \mathrm{C}$ either as a whole frozen hemisphere or as $30-40 \mathrm{~mm}$ thick tissue slaps. Because the slide holder of the LTQ-XL-Orbitrap (Thermo Fisher Scientific, Bremen, Germany) accepted only slides with a maximum size of $75 \times 25 \mathrm{~mm}$, small blocks of cortical tissue in the region of the calcarine sulcus were cut using an oscillating saw (Aesculap Oscillant) with a blade precooled to $-70{ }^{\circ} \mathrm{C}$. Cut tissue blocks were then warmed up to $-16{ }^{\circ} \mathrm{C}$ for further cutting on a cryostat (Leica CM3050, Bensheim, Germany) in serial sections of $10 \mu \mathrm{m}$ that were mounted onto glass slides and stored at $-20{ }^{\circ} \mathrm{C}$. In addition, after cutting sections for MALDI-MSI, the remaining tissue blocks were warmed to $-10{ }^{\circ} \mathrm{C}$ for cutting $30 \mu \mathrm{m}$ thick serial sections for elemental imaging analysis. This enabled the use of alternating adjacent sections for lipid and protein analysis and for cytoand myeloarchitectonic staining, whereas the directly following sections from the same tissue could be used for element analysis and histological evaluation in an alternating manner. In addition, all tissue sections used for peptide and lipid identification in MALDI-MSI experiments were afterwards rinsed in $70 \%$ ethanol for matrix removal and also used for nissl and myelin staining. These sections stained slightly weaker than non-imaged sections but allowed a direct overlay of images.

\section{Cresyl violet (nissl) staining}

For MALDI experiments, tissue sections were washed with ethanol to remove the matrix before staining. During

Table 1 Data on the human brain specimens used in this study

\begin{tabular}{llllc}
\hline Brain & Gender & Age (years) & Topography & $\begin{array}{l}\text { Post-mor- } \\
\text { tem delay } \\
\text { (h) }\end{array}$ \\
\hline 1 & M & 77 & Left occipital lobe & 5.0 \\
2 & F & 91 & Left occipital lobe & 12.5 \\
3 & F & 53 & Left occipital lobe & 4.0 \\
\hline
\end{tabular}

LA-ICP-MS, the sample is completely ablated; therefore, a consecutive $30 \mu \mathrm{m}$ section was used. Tissue sections were fixed in $4 \%$ buffered formalin for $10 \mathrm{~min}$ and rinsed $3 \times 5$ min in distilled water. Afterwards sections were stained for $20 \mathrm{~min}$ in cresyl violet solution prepared by mixing $15 \mathrm{ml}$ of a freshly filtered $2 \%$ cresyl violet solution (Chroma, Köntgen, Germany) with $85 \mathrm{ml}$ of sodium acetate buffer, $\mathrm{pH} 3.5$. Sections were rinsed in distilled water and differentiated in $70 \%$ ethanol until specific staining results became visible. Afterwards sections were rapidly dehydrated in $96 \%$ and absolute ethanol placed $2 \times$ in xylol (Merck, Darmstadt) and cover slipped with DePex.

\section{Myelin staining}

The same or consecutive sections of the tissue sections measured with MALDI and LA-ICP-MS were used. After matrix removal (see above) tissue sections were fixed in $4 \%$ buffered formalin for $10 \mathrm{~min}$ and rinsed $3 \times 5 \mathrm{~min}$ in distilled water. Formalin-fixed tissue sections were rinsed in distilled water and placed in a solution containing $50 \mathrm{ml}$ of pyridine and $25 \mathrm{ml}$ acetic anhydride for $1 \mathrm{~h}$ in the dark. Sections were rinsed $3 \times 5 \mathrm{~min}$ in distilled water and placed in an ammonium silver nitrate solution for $30 \mathrm{~min}$ in the dark. Sections were rinsed $3 \times$ in $1 \%$ acetic acid and then developed and processed according to Gallyas (1979), dehydrated and cover slipped.

\section{LA-ICP-MS measurements and data processing}

For visualization of the spatial distribution of metals, $30-\mu \mathrm{m}$ thick tissue sections were analysed using an inductively coupled plasma mass spectrometer (Agilent 7900, Agilent technologies, Japan) coupled to a laser ablation system (NWR 213, New Wave Research, Fremont, CA, USA). Following previous work (M-M et al. 2013), laser ablation was performed with a $60 \mu \mathrm{m}$ spot size and $30 \mu \mathrm{m}$ residual between lines making a y-pixel dimension of $90 \mu \mathrm{m}$. The ablated tissue material was transported into the ICP-MS through a transfer line using an Argon gas flow. The isotopes ${ }^{13} \mathrm{C},{ }^{52} \mathrm{Cr}$, ${ }^{55} \mathrm{Mn},{ }^{56} \mathrm{Fe},{ }^{63} \mathrm{Cu}$ and ${ }^{65} \mathrm{Cu}$ were monitored. Data acquisition was synchronized with the laser ablation via a trigger signal. Acquired data were processed and images reconstructed using in-house developed software.

\section{Sample preparation for MALDI-MSI}

Thin tissue sections for lipids and protein imaging were warmed up at room temperature for $2-3 \mathrm{~h}$ inside a sealed box with silica gel to avoid accumulation of condensing water, followed by 30 min drying in a vacuum desiccator. Lipid analysis was performed similar to the procedure described by (Jackson et al. 2005). In detail, $20 \mathrm{mg} / \mathrm{ml} \mathrm{DHB} \mathrm{in} \mathrm{50 \%}$ 
ethanol was directly applied as matrix substance and deposited in 24 layers using a spray device (Suncollect sprayer, SunChrom $\mathrm{GmbH}$ ). The first layer was deposited at $10 \mu \mathrm{l} /$ min, the second at $20 \mu \mathrm{l} / \mathrm{min}$, the third at $25 \mu \mathrm{l} / \mathrm{min}$ and the following layers at $30 \mu \mathrm{l} / \mathrm{min}$, resulting in the deposition of $141 \pm 3 \mu \mathrm{g}$ matrix $/ \mathrm{cm}^{2}$. Two technical replicates were prepared for each brain specimen. Due to the $\mathrm{m} / \mathrm{z}$ range limits of the Orbitrap instrument, proteins were in situ digested into peptides (Beine et al. 2016). Briefly, thawed tissue slides were washed in a series of three ethanol wash steps (70\%/70\%/100\%), 1 min per step, with gentle agitation and dried in the vacuum desiccator for $1 \mathrm{~h}$. Next, trypsin was dissolved in $20 \mathrm{mM}$ ammonium bicarbonate buffer to a $0.1 \mu \mathrm{g} /$ $\mu \mathrm{l}$ final concentration and applied for in situ digestion. The first layer was applied using a spray device at a flow rate of $5 \mu \mathrm{l} / \mathrm{min}$, followed by 17 additional layers at a flow rate of $10 \mu \mathrm{l} / \mathrm{min}$. Tissue sections were then incubated at saturated air humidity for $16 \mathrm{~h}$ at $37{ }^{\circ} \mathrm{C}$ using a homemade incubation chamber. After digestion, $30 \mathrm{mg} / \mathrm{ml}$ DHB in $50 \%$ methanol with $1 \%$ of TFA as additive was applied as matrix in 16 layers as described above, resulting in the deposition of $162 \pm 4 \mu \mathrm{g} / \mathrm{cm}^{2}$. Three technical replicates were prepared for each brain specimen.

\section{MALDI-MS measurement}

A MALDI LTQ- Orbitrap XL hybrid mass spectrometer (Thermo, Bremen, Germany) equipped with a nitrogen laser $(\lambda=337 \mathrm{~nm}$, rep. rate $=60 \mathrm{~Hz}$, spot size $=80 \times 120 \mu \mathrm{m})$ was used for mass analysis. The instrument was externally calibrated using commercial peptide standard mixtures (ProteoMass calibration kit, Sigma) for either the normal $(\mathrm{m} / \mathrm{z}$ $150-2000)$ or high $(\mathrm{m} / \mathrm{z}, 200-4000)$ mass range. Xcalibur (2.3) was used for MALDI-MSI data acquisition in positive ion mode. For lipid detection, the ion mass range was set to 400-1000 Da, with 10 laser shots per step at laser energy of $10 \mu \mathrm{J}$. For detection of tryptic peptides the mass range was set to $800-4000 \mathrm{~m} / \mathrm{z}$, with the automatic gain control engaged and laser power set to $15 \mu \mathrm{J}$. The target plate stepping distance was set to $100 \mu \mathrm{m}$ or in special case $30 \mu \mathrm{m}$ for both the $x$ - and $y$-axes. The mass resolution was 100,000 (full width at half maximum at $\mathrm{m} / \mathrm{z}$ 400). Mass spectral intensities were normalized to total ion current (TIC) at each pixel prior to image generation.

\section{MALDI-MS/MS for in situ identification of tryptic peptides}

For identification of protein-derived tryptic peptides, the same slides previously used for MSI were re-analyzed at a raster step size of $200 \mu \mathrm{m}$ using the Orbitrap mass analyzer. At each raster point, the top five most intense peaks were selected for MS/MS in a spiral raster pattern with a step size of $50 \mu \mathrm{m}$. MS/MS were acquired in the linear ion trap of the hybrid instrument, with normalized CID collision energy set to $50 \%$, isolation width of precursor ions set to $4.0 \mathrm{Da}$ and the mass range set to $m / z, 800-4000$.

\section{MALDI data analysis}

Peptide sequences were identified by matching acquired MS/MS spectra to the human UniProt proteome database (release 2015-09, 21,037 entries) using Sequest and Mascot (Matrix Science) as implemented in the software package Proteome Discoverer v 1.4.0.288 (Thermo Fisher Scientific, Waltham, MA, USA). Database searches were performed with a precursor mass tolerance of $10 \mathrm{ppm}$ and a fragment mass tolerance of $0.8 \mathrm{Da}$, enzyme specificity set to trypsin with up to two missed cleavages and allowing methionine oxidation as a dynamic modification. The identification of two matching peptides was required to consider a protein as identified. Images of the identified peptides were generated in ImageQuest v 1.0.1 (Thermo Fischer Scientific Inc., Waltham, MA, USA). Lipid species were assigned by comparison of the measured molecular masses with the Lipid MAPS database (http://www.lipidmaps.org/), the Madison Metabolomics database (http://mmcd.nmrfam.wisc.edu) and previous reports (Berry et al. 2011; Fernandez et al. 2016). For assignment, a maximum of $5 \mathrm{ppm}$ deviation between measured and theoretical mass was selected as the tolerance window. Due to the presence of salts in biological tissues, mass spectra will contain adducts of cationic salts, such as sodium or potassium apart from the protonated molecular ion $[\mathrm{M}+\mathrm{H}]$. For glycerolipid species, numbers $(x: y)$ denote the total length and the number of double bonds of the acyl chains, while for sphingolipid species numbers indicate the length and number of double bonds of the acyl chain added to those of the attached sphing-4-enine (d18:1) or sphinganine (d18:0) base (Fahy et al. 2005). Images were generated with the software packages ImageQuest v.1.0.1 (Thermo Fisher Scientific, San Jose, CA, USA) and MSI reader v.0.09 (Robichaud et al. 2013; NC State University, North Carolina, U.S.A).

\section{Results}

\section{Technical approach to complementary MALDI-MS imaging and LA-ICP-MS imaging of human V1}

To evaluate the utility of MALDI-MSI and LA-ICP-MS for the analysis of area V1, we first established a workflow that allowed us to analyze corresponding sections from the same specimen (Fig. 1). Both techniques require tissue sections of different thickness to be mounted on different glass object carriers with limited size. Therefore, we cut small tissue 


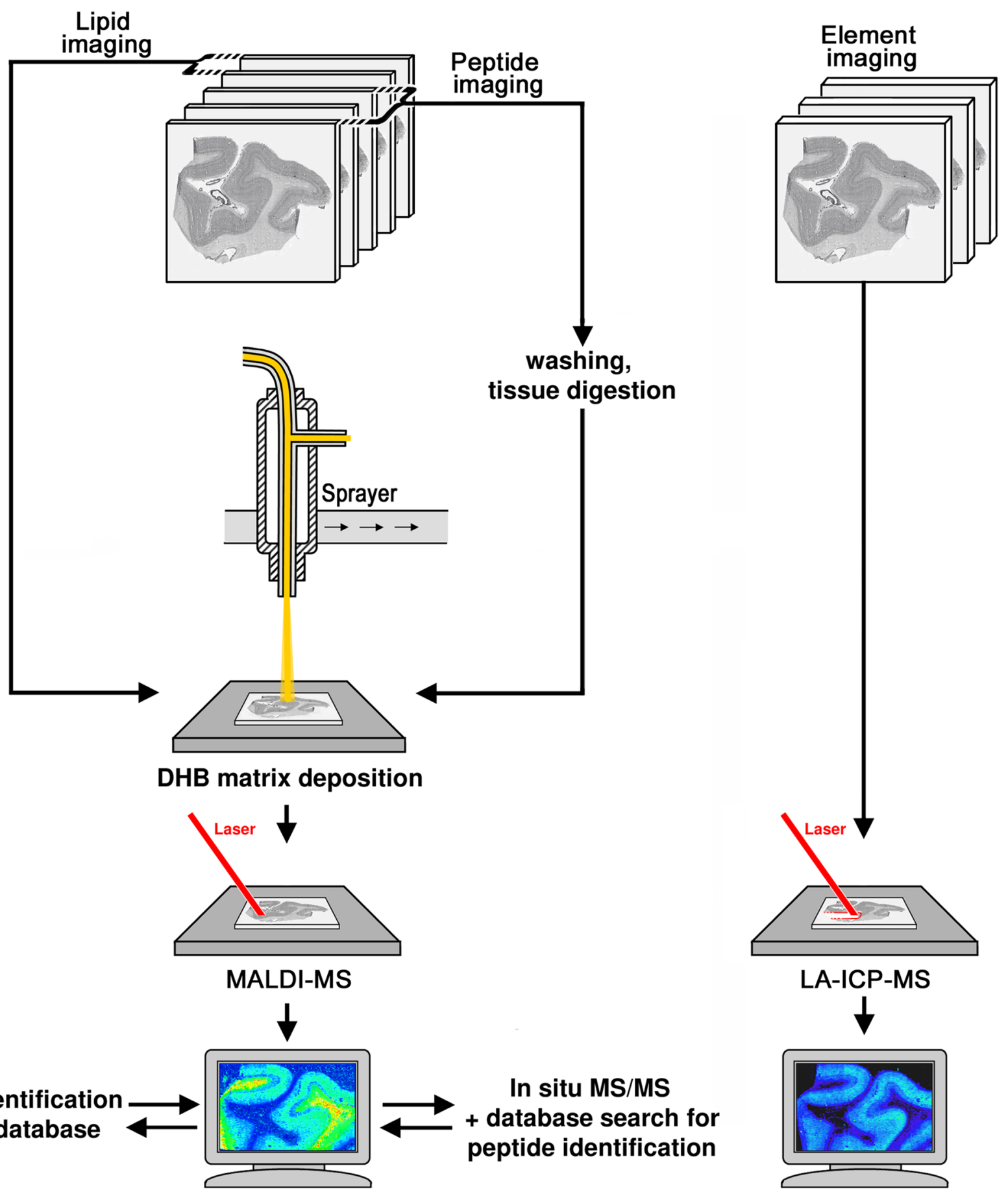

Fig. 1 Schematic workflow. Tissue blocks containing area V1 of the human cerebral cortex were cryo-sectioned into $10-\mu \mathrm{m}$ and $30-\mu \mathrm{m}$ thick sections for MALDI-MSI and LA-ICP-MSI, respectively. For lipid imaging, two sections from each brain specimen were directly coated with DHB as matrix, analyzed using high-mass resolution MALDI-MS in positive mode at 100- $\mu$ m lateral resolution. Molecular feature images were extracted for each $\mathrm{m} / z$ signal and lipids identified by comparison with lipid databases, requiring a match with a mass error $<5 \mathrm{ppm}$. For protein imaging, adjacent tissue sections were sub- jected to a series of washing steps to remove salts and lipids before on-tissue tryptic digestion of proteins to peptides, followed by matrix coating with DHB. MALDI-MS analysis in positive mode at $100-\mu \mathrm{m}$ lateral resolution yielded $\mathrm{m} / \mathrm{z}$ features that were visualized as intensity distribution images. For peptide identification, the top five most intense precursor ions at each spot were fragmented by MS/MS and sequences identified by database searches. For elemental imaging, cryosections were analyzed by LA-ICP-MS and images extracted for selected metals 
blocks of area V1 and thaw-mounted serial cryo-sections of $10 \mu \mathrm{m}$ onto glass slides for MALDI-MSI, using consecutive tissue sections for analysis of protein-derived peptides, lipids, and histological staining. For lipid imaging, sections were directly coated with matrix and analyzed, whereas protein imaging required prior on-tissue digestion before matrix deposition due to the limited mass range of the Orbitrap mass analyzer. In MALDI-MSI studies, measurement time and data size dramatically increase with higher spatial resolution, which further negatively correlates with sensitivity (Gessel et al. 2014). Considering sample size and instrument acquisition speed, we chose to analyze three human specimens in three or two technical replicates at a moderate lateral resolution (step size) of $100 \mu \mathrm{m}$. The remaining adjacent tissue blocks were cut in $30 \mu \mathrm{m}$ thick serial sections and used for element analysis by LA-ICP-MSI or histological staining. Samples were analyzed by continuous line scanning laser ablation with a focused laser beam, resulting in a horizontal resolution of $90 \mu \mathrm{m}$ (Fig. 1).

\section{Imaging of tryptic peptides identifies proteins associated with specific cortical locations}

Employing this workflow, we identified 71 peptides from 13 different proteins by in situ MALDI-MS/MS analysis and mapped their distribution by MALDI-MSI (Supplementary Table S1, Supplementary Figs. S1-13). All of the identified proteins showed clear region- and/or cortical layer-specific distribution patterns that were reproducibly observed across all technical replicates in all three specimens. Among these, five proteins showed a differential layer-specific distribution pattern that revealed the border between V1 and V2 and thereby enabled the differentiation of these two cortical areas (Fig. 2, Supplementary Table S1, Supplementary Figs. S1-5). Sections used for MALDI-MS/MS were subsequently stained and together with adjacent sections stained for myelo- or cytoarchitecture used to further associate findings with the known cortical layers and sublayers. As expected, myelin basic protein (MBP) was observed in highest concentrations in the cortical white matter (WM), while lower concentrations were found in the infragranular cortical layers, the Gennari stripe (layer IVb) and in myelin-enriched layer I (Fig. 2b, c, Supplementary Fig. S3). Neuromodulin, also known as growth-associated protein GAP43, a protein important for neuronal pathway finding and an important component of presynaptic terminals was found in the gray matter (GM) including all cortical layers with highest concentrations in the supragranular layers (II/III, Supplementary Fig. S4). In addition neuromodulin showed very low concentrations in layer $\mathrm{IVb}$ and, therefore, demarcated the border between areas V1 and V2 (Fig. 2d, brain 3, Supplementary Fig. S4). In a similar manner, microtubule-associated protein tau marked this border (Supplementary Fig. S1).
In contrast to the proteins present in neural tissue, hemoglobin subunit $\beta$ (HGS- $\beta$ ) was almost exclusively confined to intracortical blood vessels and to the intrasulcal meninges in the arachnoidea, outlining the calcarine sulcus (Fig. 2e, Supplementary Fig. S9). Overall, different protein-derived peptides showed distinct intensity gradients for GM and WM that were comparable among all three case studies (Fig. 2, Supplementary Figs. S1-13). An overlay of peptides derived from different proteins highlighted these differential expression patterns, most clearly in brain 3 (Fig. 2f).

\section{Element imaging shows strong compartmentalization of trace metals}

Element analysis by LA-ICP-MSI allowed the visualization of metals in human V1 (Fig. 3, Supplementary Fig. S14). Several metals, including $\mathrm{Cu}, \mathrm{Fe}$ and $\mathrm{Cr}$, showed strong compartmentalization (Fig. 3). For example, $\mathrm{Cu}$ was confined to the GM, and appeared particularly abundant in layers IVa, $\mathrm{b}$ and $\mathrm{c}$ (Fig. 3b). In contrast, concentration of $\mathrm{Cr}$ was high in the WM, but also in layer IVb (Fig. 3c). Accumulation of Fe was predominantly detected in blood vessels, but also in layer IV and infragranular layers (Fig. 3d). The comparison of the LA-ICP-MS images to cyto- and myeloarchitectonic images from Nissl and myelin staining, respectively, revealed that $\mathrm{Cu}$ was indeed confined with high concentration to layer IV (Fig. 4).

\section{Lipid imaging identifies markers for specific cortical layers and displays borders between cortical areas}

MALDI-MSI in positive ion mode revealed 123 lipid species of three different lipid subtypes such as glycerolipids, glycerophospholipids and sphingolipids (Supplementary Table S2, Supplementary Figs. S15-18). Of these, at least 20 showed a distinct laminar distribution pattern throughout V1 and clearly demarcated the border between V1 and V2 (Table 2, Supplementary Figure S15). The comparison with cyto- and myeloarchitectonic sections (Fig. 5a, b) showed that the ion at $m / z 697.4787$, identified as sodium adduct ion of phosphatidic acid (PA) 34:1, accumulated differentially among cortical layers (Fig. 5c). The highest abundance was observed in the supragranular layers (Fig. 5c). The lipid was also present in layer IVa (Fig. 6). The ion at $m / z 797.5919$, identified as potassium adduct ion of sphingomyelin (SM) d38:1, was localized in supragranular and infragranular layers with a characteristic reduction in layer IV (Fig. 5d). At higher magnification, SM_d38:1 was confined to sublayers IVa and IVc, sparing sublayer IVb completely (Fig. 6). In contrast, the ion at $m / z 856.5848$, identified as sodium adduct ion of phosphatidylcholine (PC)_40:6 was associated with GM and showed enhanced levels in layer IV (Fig. 5e), in particular in layer IVc (Fig. 6). The ion at $m / z 630.6181$, the potassium 
a

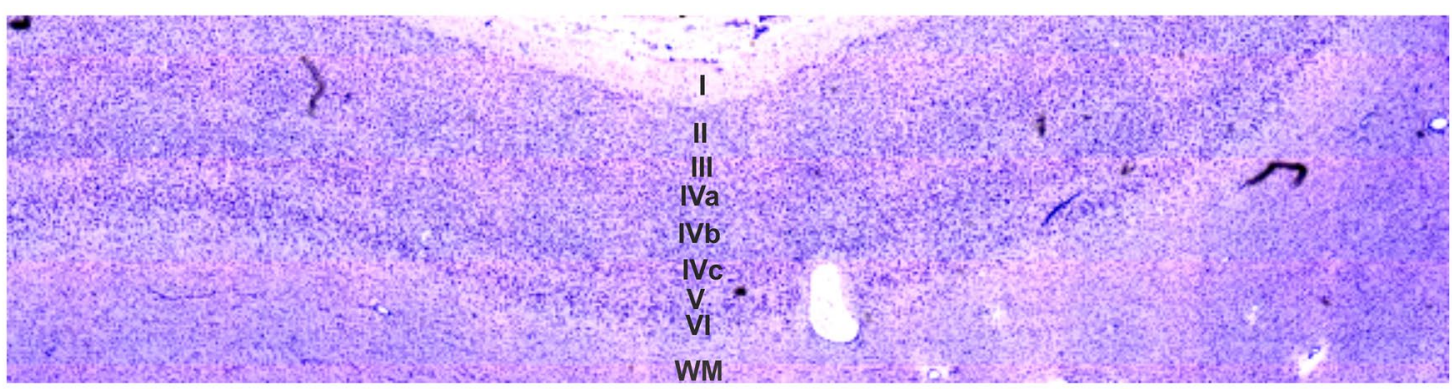

b
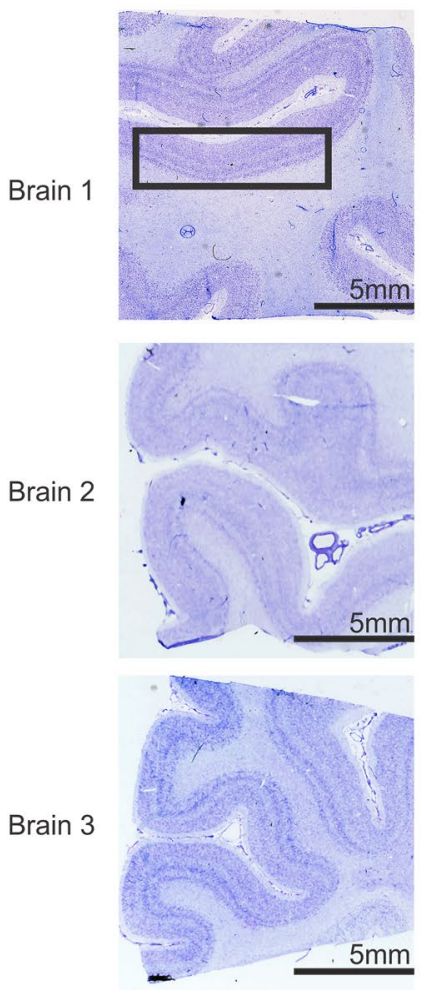

C
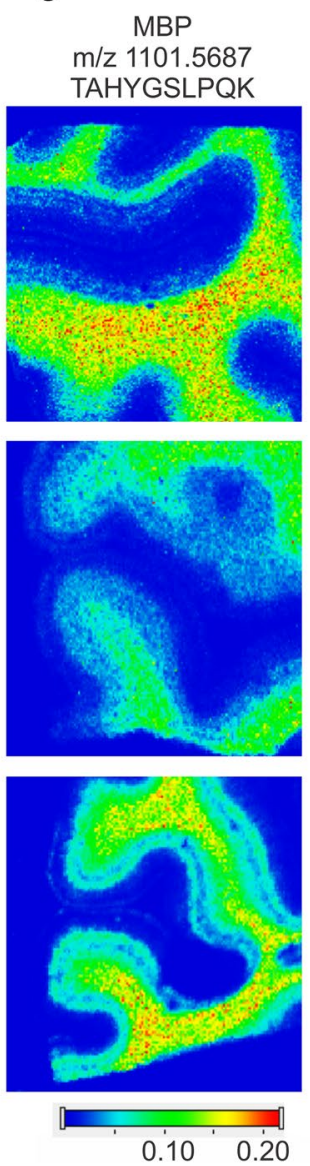

d

Neuromodulin $\mathrm{m} / \mathrm{z} 1283.50981$ EEEPEADQEHA
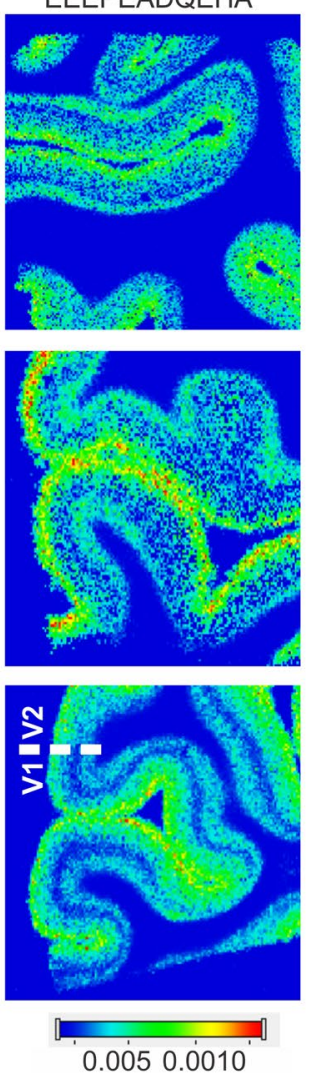

e
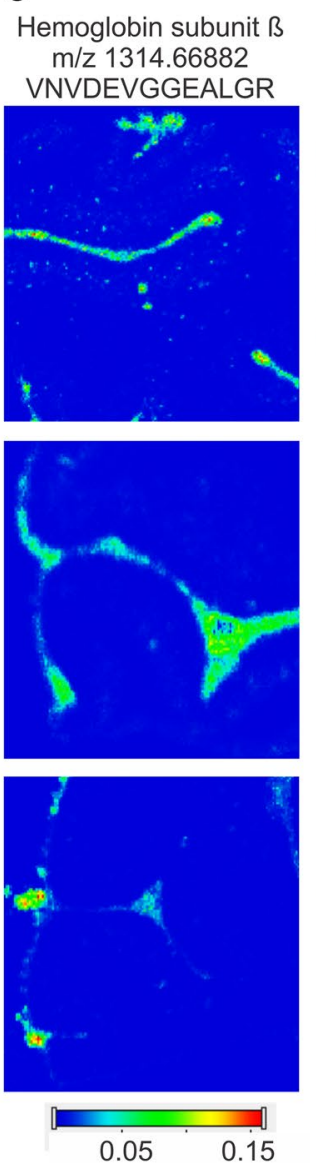

f

Overlayed image
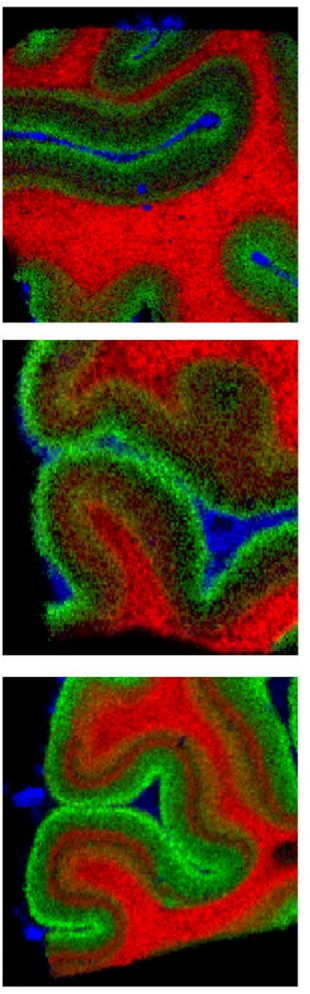

Fig. 2 Protein distributions in the human primary visual cortex determined by MALDI-MSI. a High-resolution image of a Nissl-stained section. Layer I, II, III, IVa-c, V, VI and white matter are indicated. b Nissl-stained sections from three different post-mortem brains. c-e Molecular feature images at $\mathbf{c} \mathrm{m} / \mathrm{z}, 1101.5687$, identified by MS/MS as a tryptic peptide of myelin basic protein, $\mathbf{d} \mathrm{m} / \mathrm{z}$ 1283.5098, identified as tryptic peptide of neuromodulin, e $\mathrm{m} / z$ 1314.6688, identified as

adduct of ceramide (Cer)_m40:0, was enhanced along WM, but absent or reduced to non- detectable amounts in layer IVb (Fig. $5 \mathrm{~g}$ ). In contrast, the ion at $\mathrm{m} / \mathrm{z}$ 768.5879, the protonated ion of PC_O-34:0, was abundant in WM including layer IVb (Fig. 5f). In summary, we were able to identify tryptic peptide of hemoglobin $\beta$. f Overlay of the three peptide images highlighting their discrete distribution, MBP as red, neuromodulin as green and hemoglobin $\beta$ as blue. Spectra were recorded in positive ion mode at $100-\mu \mathrm{m}$ lateral resolution. Black scale bar in panel $\mathbf{b}$ : $5 \mathrm{~mm}$ (applies horizontally to all images of the corresponding specimen). Color scales: Peptide ion intensity in arbitrary units (applies vertically to all images of the corresponding peptide)

lipids specifically accumulating in different cortical layers and even sublayers of V1 or the WM.

To clarify if and how lipids differed between V1 and neighboring area V2, a tissue section containing the border between V1 and V2 was measured with the highest spatial resolution possible of $30 \mu \mathrm{m}$. Two lipid ions, the potassium 


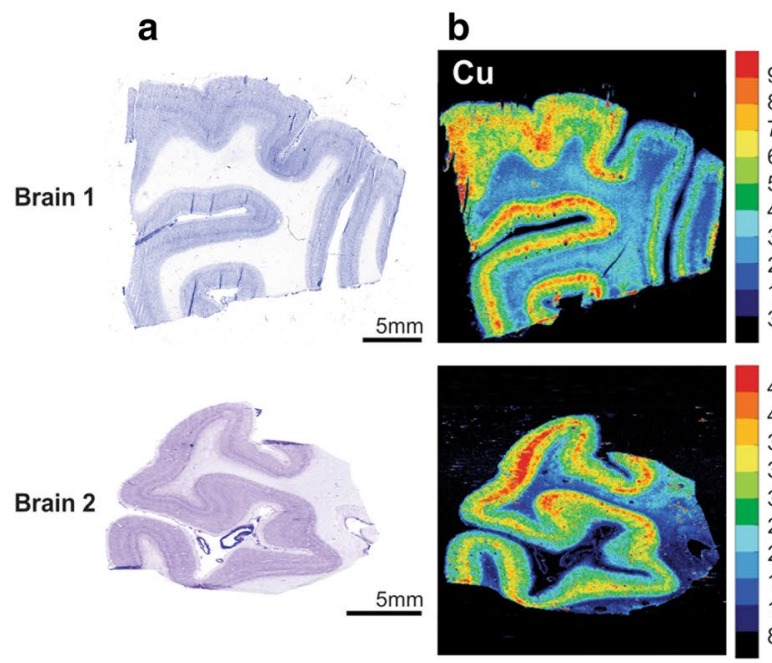

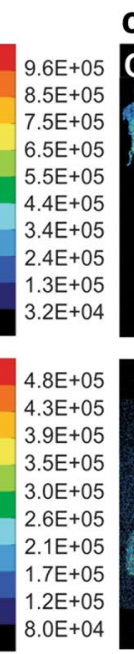

C
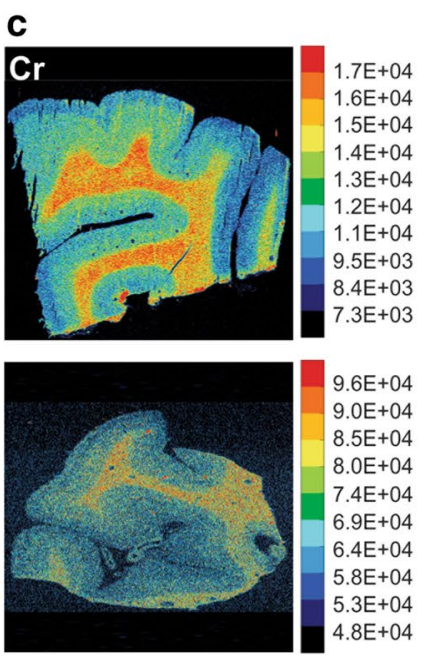

d
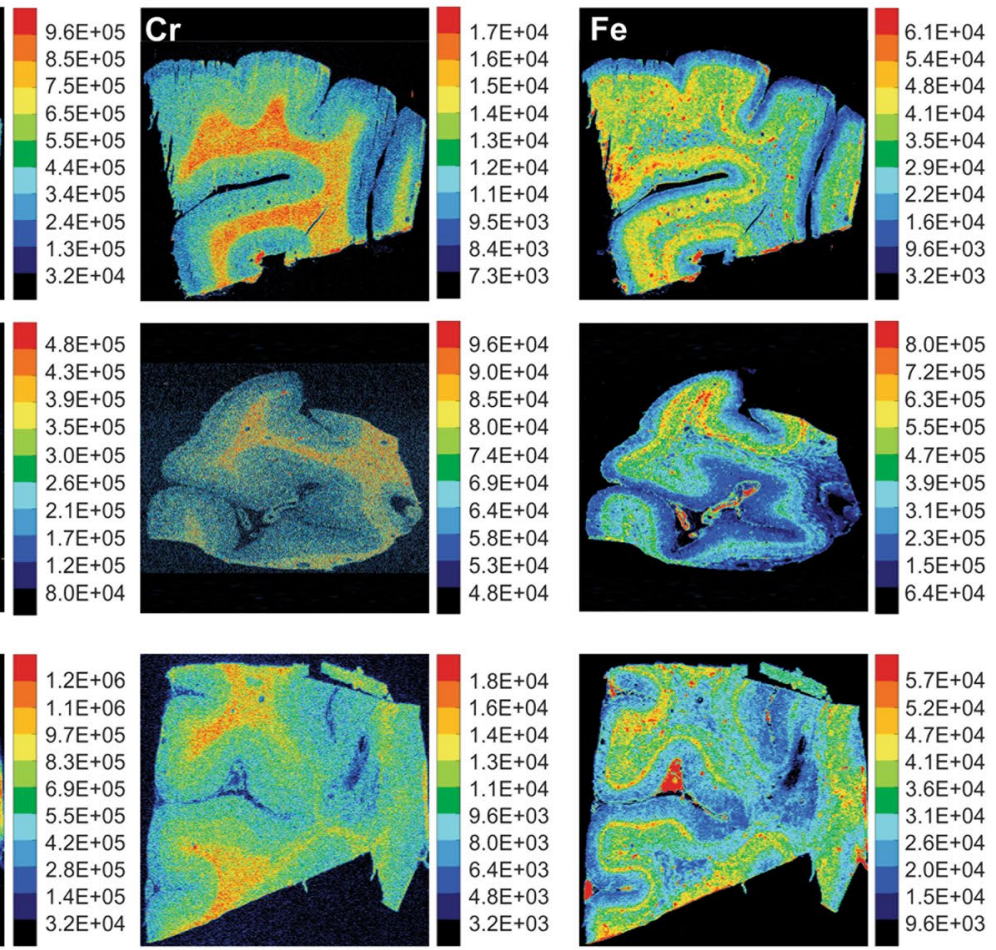

$3.2 \mathrm{E}+04$
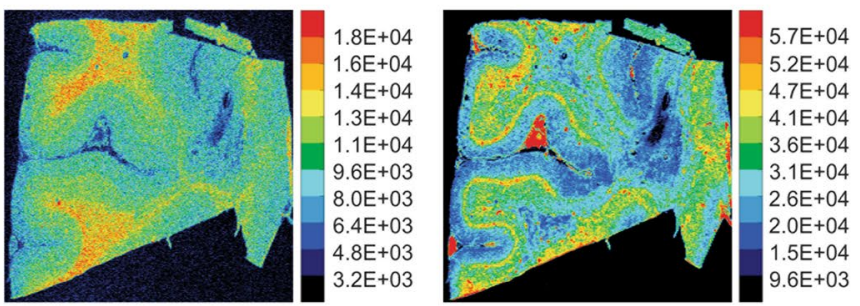

Brain 3

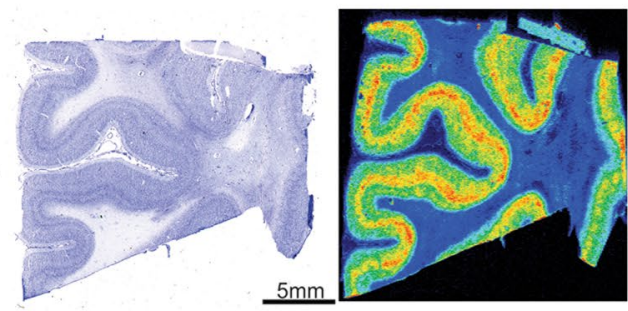

Fig. 3 Bio-imaging of metals in area V1 of the human brain using LA-ICP-MS a Nissl-stained sections. b-d MS images obtained from monitoring ${ }^{65} \mathrm{Cu},{ }^{52} \mathrm{Cr}$ or ${ }^{56} \mathrm{Fe}$, respectively. Colors represent element

adduct ion of SM_d42:2 (Fig. 7a) and the sodium adduct ion of PC_40:6 (Fig. 7b), clearly demarcated the border of V1 and V2. A high concentration of SM_d42:2, was found in layer IVb of area $\mathrm{V} 1$, but disappeared when moving to V2 (Fig. 7a, d). At the same time PC_40:6 seemed to be specific of cortical layer IV, and also disappeared at the border to V2 (Fig. 5b). As visualized in an overlay of the images (Fig. 7c), SM_d42:2 specifically labeled sublayer IVb, whereas PC_40:6 was confined to IVc. Thus, several lipids distinguished the neighboring cortical areas V1 and V2 based on differences in their laminar concentration.

\section{Discussion}

In the last decade, MSI techniques have been extensively used to study the distribution of different elements, drug compounds and endogenous biomolecules such as lipids, peptides, and proteins in various tissues (Becker et al. 2010; Shariatgorji et al. 2014; Mathur et al. 2009). The aim of the current study was to test whether commercial MALDI-MSI and LA-ICP-MSI setups would allow the identification of cortical areas in human brain sections based on element and biomolecule distribution patterns, using V1 as a region that intensity in arbitrary units, individually scaled for each image. Scale bar: $5 \mathrm{~mm}$ (applies to all images of the corresponding specimen)

is particularly well characterized by microanatomical and functional means (Hubel and Wiesel 1977; Hinds et al. 2009; Zilles et al. 2009; Palomero-Gallagher and Zilles 2017).

\section{Protein distribution patterns}

In situ MS/MS analysis identified 71 peptides from 13 proteins. Many additional peptide signatures were observed, but not identified due to their low concentration, which precluded acquisition of high-quality MS/MS fragmentation spectra in situ. Although peptide identifications can be increased by parallel processing of adjacent tissue sections, followed by peptide extraction and analysis by nanoLC-MS/MS (Heijs et al. 2015), we did not follow this approach because the limited dataset already contained distinct protein/peptide patterns that were reproducibly observed in each biological and technical replicate. However, it should be noted that this does not hold true at the level of normalized intensity due to a variety of biological (differing age, gender and unknown case history; Table 1) and technical factors (different post-mortem delays, variability in tryptic digest efficiency).

Nevertheless, the peptide patterns showed a well-defined laminar resolution. Peptides derived from MBP were found 

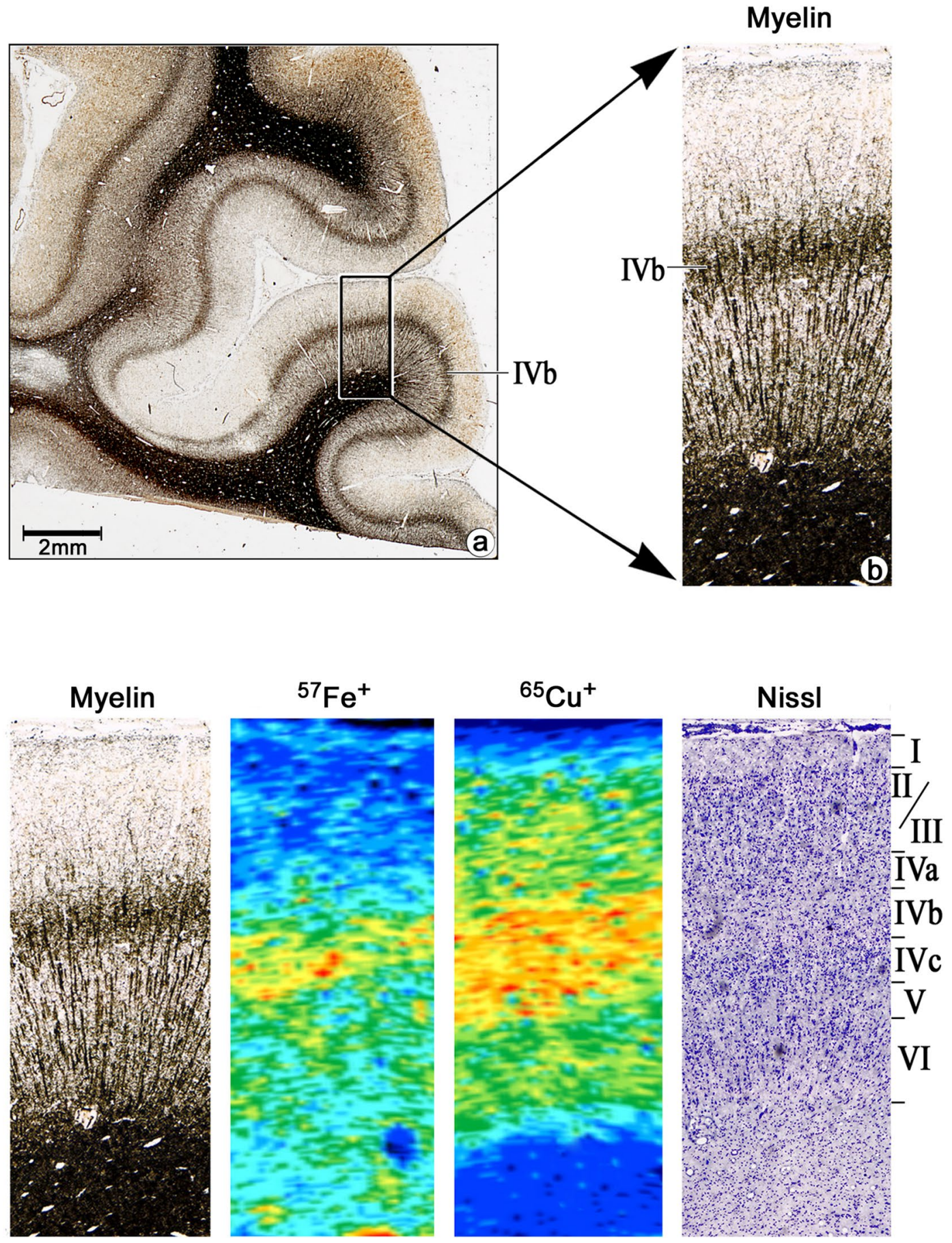

Fig. 4 Higher magnification of a representative LA-ICP-MS image of ${ }^{65} \mathrm{Cu}$ and ${ }^{57} \mathrm{Fe}$ compared to cyto- and myeloarchitecture as reveal in neighboring sections of the same brain. Roman numbers indicate

in the $\mathrm{WM}$ and in layers IVb and I, as previously described (Horton and Hocking 1997). Layer IVb is an unequivocal characteristic of V1 that is absent in V2, MBP peptides therefore clearly demarcated V1. In contrast, neuromodulin (GAP43, Van Lookeren Campagne et al. 1989; Leu et al. 2010; Holahan 2017) and microtubule-associated protein tau cortical layers; IVb serves as the major target for afferents from the lateral geniculate body. Scale bar: $2 \mathrm{~mm}$

demarcated layer $\mathrm{IVb}$ and, therefore, also V1 due to their lowest laminar concentration in this sublayer. Synapsin, a protein linked to synaptic transmission, was mainly enriched in supragranular layers, barely detected in layer IV, and then slightly increased again in the infragranular layers. This distribution was in accordance with previous studies reporting 
Table 2 Lipids with differential distribution pattern in V1 and V2 as determined by MALDI-MSI. Lipids were identified by comparison of the experimentally determined high-accuracy mass and their theorical $\mathrm{m} / \mathrm{z}$ value

\begin{tabular}{|c|c|c|c|}
\hline Experimental $\mathrm{m} / \mathrm{z}$ & Lipid & Theoretical $\mathrm{m} / \mathrm{z}$ & Error (ppm) \\
\hline 709.5139 & $\begin{array}{l}\text { [PA_O- } \\
\text { 36:2+Na]+[/ } \\
\text { PA_P- } \\
36: 1+\mathrm{Na}]+\end{array}$ & 709.5143 & 0.56 \\
\hline 776.5906 & $\begin{array}{l}{\left[\mathrm{HexCer}_{-}\right.} \\
\quad \mathrm{d} 38: 2+\mathrm{Na}]+\end{array}$ & 776.5928 & 2.83 \\
\hline 778.6082 & $\begin{array}{l}{\left[\mathrm{CerP}_{-}\right.} \\
\quad \mathrm{d} 44: 2+\mathrm{Na}]+\end{array}$ & 778.6085 & 0.38 \\
\hline 785.4502 & [PA_40:7+K]+ & 785.4518 & 2.03 \\
\hline 797.5926 & [SM_d38:1+K]+ & 797.5933 & 0.87 \\
\hline 828.5503 & [PC_38:6+Na]+ & 828.5514 & 1.30 \\
\hline 832.5819 & {$\left[\mathrm{PC} \_38: 4+\mathrm{Na}\right]+$} & 832.5827 & 0.96 \\
\hline 838.617 & $\begin{array}{l}{\left[\mathrm{PICer}_{-}\right.} \\
\quad \mathrm{d} 38: 0+\mathrm{H}]\end{array}$ & 838.6168 & -0.23 \\
\hline 844.5252 & [PC_38:6+K]+ & 844.5253 & 0.11 \\
\hline 848.6368 & $\begin{array}{l}\text { [GlcCer_- } \\
\text { d42:2+K]+ }\end{array}$ & 848.6375 & 0.82 \\
\hline 851.6387 & {$\left[S M \_d 42: 2+K\right]+$} & 851.6403 & 1.87 \\
\hline 856.581 & {$\left[\mathrm{PC} \_40: 6+\mathrm{Na}\right]+$} & 856.5827 & 1.98 \\
\hline 864.6328 & $\begin{array}{l}\text { [PI-Cer } \\
\quad \mathrm{d} 40: 1+\mathrm{H}]\end{array}$ & 864.6324 & -0.46 \\
\hline 865.6544 & {$\left[S M \_d 43: 2+K\right]+$} & 865.6559 & 1.73 \\
\hline 866.6465 & $\begin{array}{l}\text { [PI-Cer_ } \\
\quad \mathrm{d} 40: 0+\mathrm{H}]\end{array}$ & 866.6481 & 1.84 \\
\hline 870.5394 & {$[$ PC_40:7+K]+ } & 870.541 & 1.83 \\
\hline 872.5567 & {$[$ PC_40:6+K]+ } & 872.5566 & -0.11 \\
\hline 876.6693 & $\begin{array}{l}{\left[\mathrm{GlcCer}_{-}\right.} \\
\mathrm{d} 44: 2+\mathrm{K}]+\end{array}$ & 876.6689 & -0.45 \\
\hline 879.6709 & {$\left[S M \_d 44: 2+K\right]+$} & 879.6716 & 0.79 \\
\hline 896.4821 & {$\left[\mathrm{PS} \_42: 9+\mathrm{K}\right]+$} & 896.4838 & 1.89 \\
\hline
\end{tabular}

Cer ceramide, GlcCer glucosylceramide, $P C$ phosphatidylcholine, $P A$ phosphatidic acid, $P S$ phosphatidylserine, $S M$ sphingomyelin, $P I-C e r$ ceramide phosphoinositol

that thalamocortical terminals arriving in layer IV, which provide the driving input to V1 from the lateral geniculate nucleus, do not use synapsin (Owe et al. 2013). Furthermore, similar distribution patterns were observed for myristoylated alanine-rich C kinase substrate (MARCKS) and neuromodulin. These two presynaptic proteins, which are both involved in regulating the dynamics of the actin cytoskeleton at the synaptic membrane (Laux et al. 2000) and are considered of diagnostic value for neurodegenerative diseases (Remnestal et al. 2016), showed a distinct absence in layer IV and, therefore, differentiated V1 from V2. Both MARCKS mRNA and neuromodulin mRNA were co-expressed in monkey V1 (Higo et al. 2002, 2004). However, intense signals in layers $\mathrm{IVb}, \mathrm{V}$ and VI were only observed for MARCKS (Higo et al.
2002). In contrast, we observed both proteins in layers $\mathrm{V}$ and VI (Supplementary Figs. S8, S11). Neurofilament light protein was predominantly observed in the GM, sparing supragranular layers, in agreement with a mesh-like distribution in layer IVa as described by immunohistochemistry (Preuss et al. 1999). The glial fibrillary acidic protein (GFAP), a protein mainly expressed in astrocytes, was mainly confined to layer I although immunohistochemical studies have shown that GFAP-positive astrocytes accumulate more in supragranular layers than in infragranular layers and WM, and that highest GFAP expression occurs in those cells forming the glia limitans (Eilam et al. 2016). It is possible that the concentration of GFAP in layers II/III is so much lower compared to layer I (or astrocytes forming the glia limitans) that it did not reach the detection limit of our method.

Overall, MALDI-MSI data showed good agreement with the distribution patterns of proteins previously studied in V1. Moreover, we identified peptide signals derived from brain acidic soluble protein (BASP-1), actin cytoplasmic protein and stathmin, all of which were previously not described in the primary visual cortex. BASP-1, a presynaptic protein involved in several cellular processes e.g. during brain development in rodents (Kropotova et al. 2013), was most abundant in supragranular layers including layer IV and is missing in layer IVb, which also made it possible to differentiate V1 from V2. Stathmin, a protein involved in regulating cytoskeletal dynamics and adult neurogenesis (KedrackaKrok et al. 2016; Martel et al. 2016), was detected in supragranular layers and showed lower intensities in infragranular layers while sparing layer IVb completely.

Bauernfeind et al. (2015) recently studied protein distribution in different cortical areas, including cingulate cortex, motor cortex or primary visual cortex, and observed similar patterns of protein expression among supra- and infragranular layers of neocortex that were consistent with the cytoarchitectonic features independent of the region. Remarkably, no distinct signature of V1 was reported, whereas we observed distinct differences between V1 and V2 due to differential protein accumulation particularly in layer $\mathrm{IVb}$. This may be explained by the different sets of proteins detected by the different technical approaches employed: Bauernfeind et al. (2015) analyzed distinct matrix spots with $200 \mu \mathrm{m}$ diameter and detected intact proteins in a mass range between 2 and $40 \mathrm{kDa}$ using an MALDI-TOF mass spectrometer, whereas we detected peptides after in situ protein digest and coating of the entire sections with a thin layer of matrix and thereby indirectly observed also proteins with a higher molecular weight, with little overlap between the two datasets. Finally, in comparison with immunohistochemical approaches where antibody cross-reactivity is hard to exclude, our in situ MS/MS analysis provided direct evidence for the sequence of the visualized peptides. 
Fig. 5 Lipid distributions in the human primary visual cortex. a Myelin staining. b Nissl staining of sections adjacent to (a). c-g Lipid distribution images measured by MALDI-MSI tissue sections directly adjacent to the Nissl staining shown in (b). Images show the distributions of ions at $\mathbf{c} m / z$ 697.4787, identified as PA_34:1+Na, d $m / z$ 797.5919, identified as SM_d38:1+K, e $m / z$ 856.5848, identified as PC_40:6+ Na,

f $m / z$ 630.6181, identified

as Cer_m40:0 + K and $\mathbf{g} \mathrm{m} / \mathrm{z}$ 768.5879 , identified as PC_O$34: 0+H$. Images were recorded in positive ion mode at $100 \mu \mathrm{m}$ lateral resolution. Scale bar in b $5 \mathrm{~mm}$, applies vertically to all images of the corresponding specimen. Color bars indicate normalized lipid ion intensities (arbitrary units, applies horizontally to the corresponding lipid across all specimens)

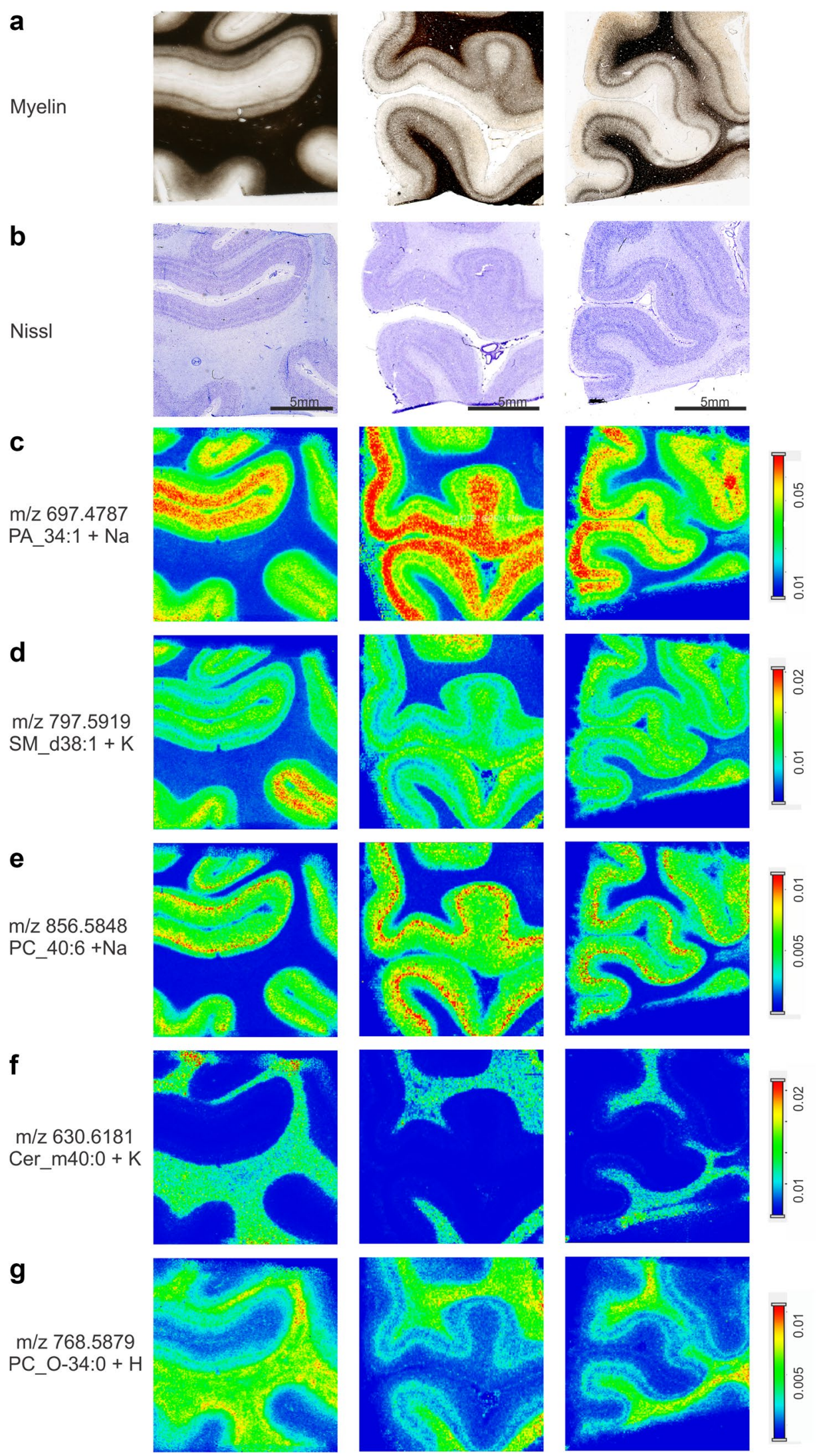


Fig. 6 Lipid images compared to cyto- and myeloarchitecture. Note the different concentrations of the three lipids in the different cortical layers: while PA-34:0 + H shows maximal concentration in the supragranular layers, PC-40:6 + Na reaches maximal values in layer IVc; SM-d38:1 + K has minimal values in layer IVb, and medium concentrations in supra—and infragranular layers. For all three lipids, the concentrations drop down in the white matter, indicating that the lipids are associated to neuronal and/or glial cells. The images are from the brain 2 . Scale bar: $2 \mathrm{~mm}$
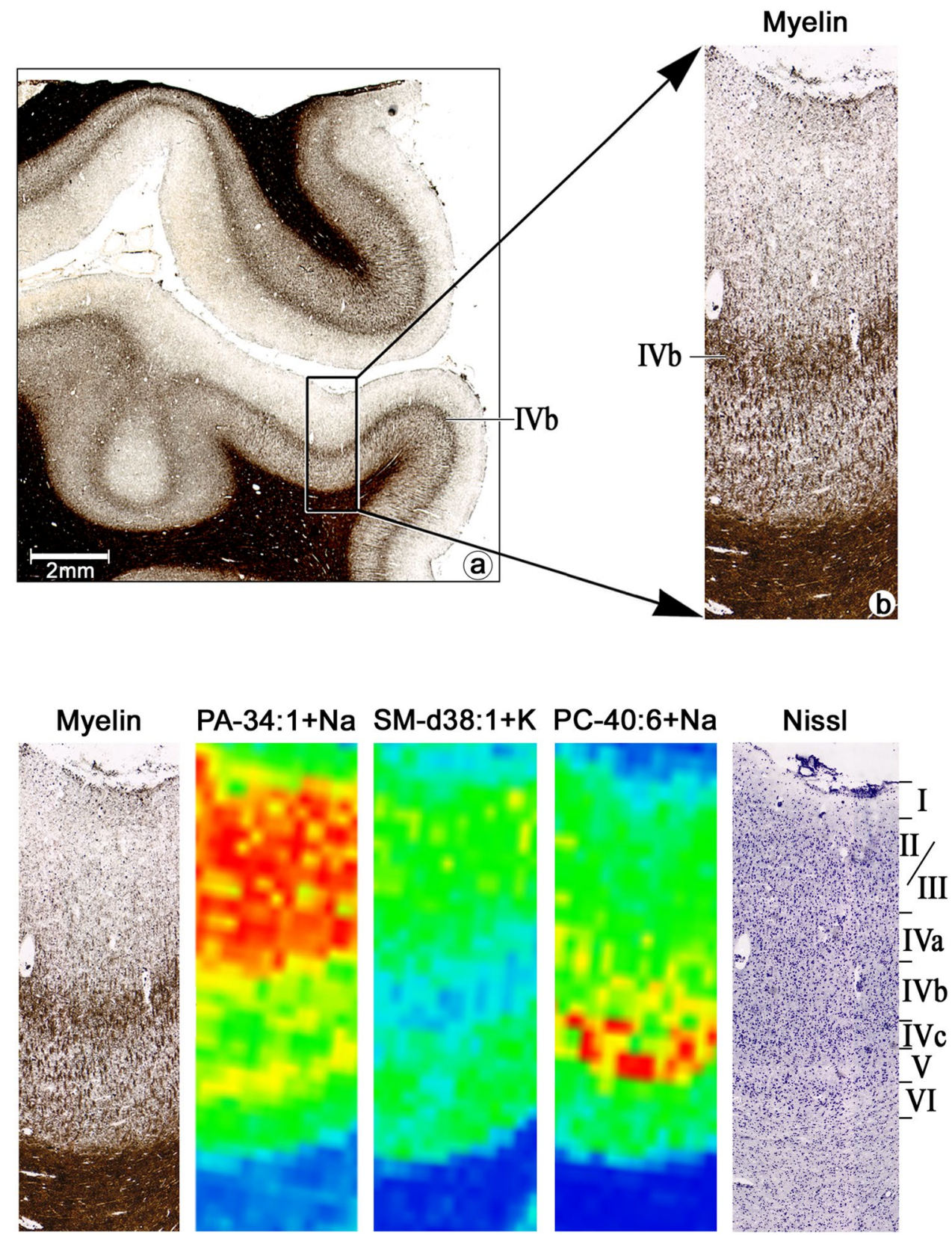

\section{Metal distribution patterns}

Metal ion homeostasis is severely affected in a variety of neurodegenerative diseases, including Alzheimer's disease, Parkinson's disease (Bourassa and Miller 2012) and traumatic brain injury (Portbury et al. 2016). Specifically affected cortical areas can be identified by LA-ICP-MSI, which measures concentration of metals and other elements in a spatially resolved manner (Sussulini et al. 2017). Such findings make it necessary to study the distribution of metals in a more systematic way in different regions of brains of healthy controls. Here we mapped the element distributions in area V1. Discrete patterns for selected elements were found. For example, copper was distributed across the cortical cross-section, and appeared enriched in layer IV (Fig. 3). This pattern was similar to that described for $\mathrm{Cu}$ in the human insular cortex (Dobrowolska et al. 2008) and in agreement with previous reports indicating that $\mathrm{Cu}$ was more abundant in GM than WM in nonhuman primate brain (Bonilla et al. 1984; Ramos et al. 2014; Knauer et al. 2017). Iron was observed in blood vessels, as expected due to its well-known association with hemoglobin, but also along layer IV and infragranular layers. Key proteins of iron homeostasis are also involved in $\mathrm{Cu}$ regulation (Mueller et al. 2009), which may explain the similar distributions of $\mathrm{Fe}$ and $\mathrm{Cu}$ in layer IV and infragranular layers. 


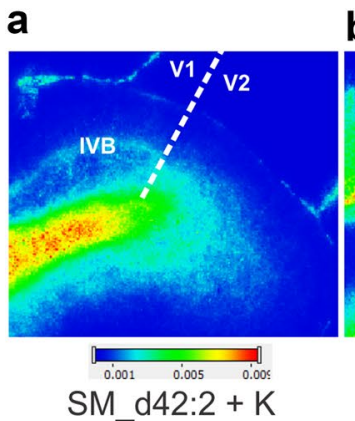

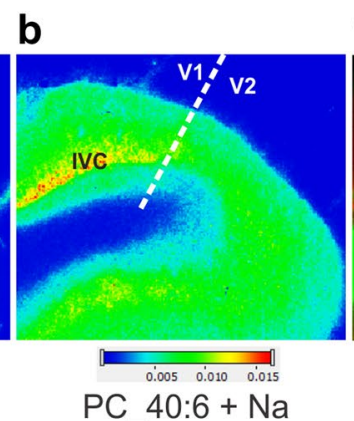
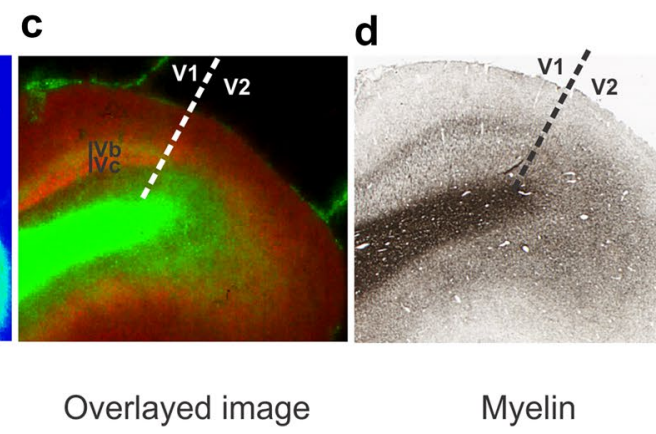

PC_40:6 + Na

Overlayed image

Myelin f

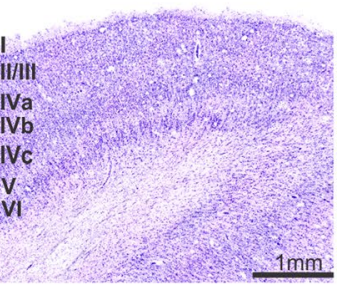

Nissl
Fig. 7 Area-specific lipid distributions in the human visual cortex reveal the border between area V1 and the secondary visual cortex, area V2. a The ion at $m / z, 851.6387$ identified as SM_d42:2 increases in layer IVb (Gennari stripe) and infragranular layers at the transition of V1 and V2. b The distribution of ion at 856.581 identified as PC_40:6 also indicates the border of V1 and V2 by a decrease in layer IVc when moving from V1 to V2. c Overlayed images of SM_

\section{Patterns of lipid distribution}

Lipids represent the largest component of the brain ( $\mathrm{Li}$ et al. 2017). Not only the amount, but also the number of cerebral lipid species increased along the phylogenetic line from mice over apes to man, as well as with age within a single species (Bozek et al. 2015; Li et al. 2017). This suggests that lipids might offer a key to improve our understanding of the connectome and higher cognitive functions that evolved in primates (Bozek et al. 2015; Li et al. 2017). For example, the composition of phospholipids (PLs) with varying acyl chain length and the number of unsaturated $\mathrm{C}=\mathrm{C}$ double bonds define the characteristics and functional efficacy of neural membranes (Van Meer et al. 2008). Apart from their structural role, polyunsaturated lipids are further precursors for important second messengers such as arachidonic (C20:4), eicosapentaenoic (C20:5), docosapentaenoic (C22:5) and docosahexaenoic (C22:6) acids (Guichardant et al. 2011) which are partly known to be involved in neuronal signaling (Gantz and Bean 2017). This is in agreement with the recently proposed hypothesis of "small molecule cotransmission" (Nusbaum et al. 2017), which suggests that membrane compounds regulate neurotransmitter signaling independently and in conjunction transmitter receptors. Furthermore, lipid rafts have been identified as important mediators of mGlu1 receptor-mediated signaling (Roh et al. 2014). It is, therefore, of great interest to obtain detailed information on the distribution of lipids in the brain, and to correlate their occurrence with the role of these areas in certain functional networks. Mass spectrometry-based methods such as MALDI-MSI, DESI-MS, SIMS, nanoparticlelaser desorption ionization or $40 \mathrm{keV}$ argon cluster SIMS (Skraskova et al. 2015; Mohammadi et al. 2016; BodzonKulakowska et al. 2017) are uniquely suited to obtain such data as it is generally not possible to use techniques such as $\mathrm{d} 42: 2+\mathrm{K}$ (green) and PC_40:6 + Na+ (red) reveals distinct distribution in different layers. d Myelin-stained tissue section showing the border between V1 and V2. f Nissl-stained tissue section with layer I, II, III, IVa-c, V, VI. The spectra were recorded in positive ion mode at $30-\mu \mathrm{m}$ lateral resolution. The images are from the brain 2 . Scale bar: $1 \mathrm{~mm}$ (applies to all panels)

fluorescence tags and fluorescence microscopy to define the location of the relatively small and dynamic lipids.

In this study, we revealed unique regional distribution patterns of more than 120 lipid species based on high-accuracy mass measurements. Specific lipid species were found in either GM or WM, enriched in distinct cortical layers or sublayers. Among all observed lipids, we found 20 species with a relevant distribution demarcating the border between V1 and V2, mostly based on a distinct sublayer-specific localization. For instance, PC O-34:0 was highly enriched in subcortical WM, whereas PC-40:6 was neither observed in WM nor in supragranular GM. This may indicate specific function(s) confined to layer IVc, a cortical sublayer of V1 that also showed specific protein expression related to ocular dominance columns in primate experiments (Ataman et al. 2016).

PCs are the most abundant lipids in the occipital cortex, at a concentration of $19 \mu \mathrm{mol} / \mathrm{g}$ tissue (Abbott et al. 2013). We identified 23 different PC species, each with distinct distribution patterns. Several PCs were specifically observed in layer IVc, including PC_40:6, PC_40:7 and PC_38:6 (Figs. 5, 6; Table 2, Supplementary Fig. S15). These PCs contain the long-chain polyunsaturated docosahexaenoic acid (DHA) as FA, which is known to play an important role within the visual system, in neurotransmission at synapses and during brain development (Sugiura et al. 2009; Sugiura and Setou 2009). Furthermore, these lipids are critical for the maturation of visual functions (Uauy et al. 2001). Interestingly, fibers arriving with the Radiatio optica from the lateral geniculate nucleus via layer IVb terminate with synaptic contacts mainly at layer IVc (Casagrande and $\mathrm{Xu}$ 2004). Specific accumulation of polyunsaturated PCs in this region may indicate an important role within the cell membranes contributing to synaptic transmission. Consistent with that hypothesis, a loss of PC_40:6 and PC_40:7 has 
been observed in the parieto-occipital cortex of Parkinson patients suffering from GM atrophy and visual hallucinations (Cheng et al. 2011). Moreover, saturated PC's such as PC_30:0, PC_32:0, PC_33:0 or PC_34:0 were found in the GM and specifically enriched in supragranular layers. The latter contains high numbers of neurons and dendrites and also higher amounts of palmitic acid (16:0) than WM (Skinner et al. 1993; Sugiura and Setou 2009; Veloso et al. 2011a, b; Martinez-Gardeazabal et al. 2017). In contrast, PCs containing 18:0, 18:1 or 18:2 as FAs are located in WM, for example, PC_33:2, PC_36:2, PC_36:1 or PC_38:2. This is in agreement with reports that showed 18:1 FA accumulation in myelin sheets (Kishimoto et al. 1969; Veloso et al. 2011a, b).

Similar to PCs, PLs containing palmitic acid, such as PA_32:1 or PA_34:1, were enriched in supragranular layers. Likewise, a PA with polyunsaturated FA, PA_40:7, accumulated specifically in layer IVc. PS_40:6, which is the most abundant PS in brain (Hicks et al. 2006), and PS_42:9 were observed along the GM, but not in layer IVc. The vast majority of the sphingolipids that we have detected are distributed along the WM and blood vessels exceptions are, for example, SM_d33:1 and SM_d38:1. The former is specifically accumulating in the supragranular layers, whereas the latter is distributed along the GM except in layer IVb. It has been reported that SM_d38:1 is decreased in Alzheimer disease in the prefrontal cortex (Chan et al. 2012). Glucosylceramide (GlcCer), which are present in higher concentration in adults compared to infant brain ( $\mathrm{Li}$ et al. 2017), were mainly present in the WM. Also all other lipid classes, e.g. glycerolipids, showed specific distribution patterns with enhanced or reduced amounts confined to specific cortical layers. However, the function(s) of these lipids still need to be established.

\section{MALDI imaging of lipids resolves borders between cortical areas}

Some of the tissue blocks contained not only area V1, but also parts of neighboring area V2. The border could be clearly identified by lipid biomarkers. To investigate this intricate feature in more detail, we performed additional experiments at increased resolution of $30 \mu \mathrm{m}$, and found that certain lipids were associated specifically with WM and the Gennari stripe (IVb), while others were specifically confined to layer IVc. For example, PC_40:6 clearly changed the distribution pattern at border V1/V2. Therefore, the human lipidome represents a new modality for functional cortical parcellation at the sublaminar level. Further studies are warranted to explore to which degree this will be applicable for other cortical and subcortical regions as well.

\section{Conclusions}

LA-ICP-MSI and MALDI-MSI were employed for mapping element, protein and lipid distribution in area V1 of the human brain. In most cases, regional and laminar distribution patterns faithfully reflected the well-known cytoarchitectonic features of V1 which was further verified by both cell body and myelin staining. In addition, selected lipids appeared associated with cells confined to specific cortical layers. This demonstrates that multimodal proteomics, lipidomics and metallomics analysis with highly explorative MSI techniques reveals molecular markers for human brain mapping, independent of prior knowledge, target-specific reagents and at high resolution close to the cellular level. The region-specific distribution patterns of these molecules are comparable to those observed by comprehensive comparative studies of ligand binding sites for neurotransmitter receptors among functional cortical areas (e.g. Palomero-Gallagher and Zilles 2017). Both MALDI-MS and LA-ICP-MS imaging techniques still suffer from limitations such as lower spatial resolution compared to histochemistry, lower sensitivity compared to liquid mass spectrometry and necessary practical compromises between resolution, sensitivity and required measurement time (Gessel et al. 2014). However, technical (Kompauer et al. 2017) and computational (Van de Plas et al. 2015) advances already allow accelerated measurements and enabled dramatically improved lateral resolution. It should be noted that individual differences observed in metal, lipid and protein concentration among the three brain specimens studied here might be associated with different age, relate to different pre-mortem conditions or differential post-mortem handling such as delay until freezing, or differences in trypsin digest efficiency. The distribution patterns should, therefore, only be compared qualitatively, as a quantitative comparison would require higher sample numbers.

Lipids play important, but still incompletely understood roles in brain evolution and higher cognitive functions (Bozek et al. 2015; Li et al. 2017). MALDI-MSI currently offers the only option to elucidate the cerebral distribution of lipids as key determinants of cell membrane fluidity and dynamics and is, therefore, poised to play a crucial role in their integration in functional brain models (Zhao et al. 2015; Glasser et al. 2016). Furthermore, MALDI-MSI may provide a key to test the new "Small molecule co-transmission" hypothesis (Nusbaum et al. 2017) in greater detail and in a region-specific manner and thereby open avenues for a comprehensive understanding of neurotransmission-related processes and receptor trafficking.

Acknowledgements This work was supported by an instrument grant from the Deutsche Forschungsgemeinschaft (AM 118/7-1), 
and received some funding from the European Union's Horizon 2020 Framework Program for Research and Innovation under Grant Agreement No 720270 (Human Brain Project SGA1). We thank Dr. J. Sabine Becker and Prof. Karl Zilles for their important contributions that made this project possible. We thank Mrs.C. Opfermann-Rüngeler (Dept. of Anatomy, Heinrich-Heine-University of Düsseldorf) for assistance in preparing Fig. 1. Expert technical assistance was provided by L. Igdalova (Heinrich-Heine-University of Düsseldorf).

\section{Compliance with ethical standards}

Conflict of interest The funding sources had no influence on the design and interpretation of the study. The authors are not aware of any conflict of interest.

Open Access This article is distributed under the terms of the Creative Commons Attribution 4.0 International License (http://creativeco mmons.org/licenses/by/4.0/), which permits unrestricted use, distribution, and reproduction in any medium, provided you give appropriate credit to the original author(s) and the source, provide a link to the Creative Commons license, and indicate if changes were made.

\section{References}

Abbott SK, Jenner AM, Mitchell TW, Brown SH, Halliday GM, Garner B (2013) An improved high-throughput lipid extraction method for the analysis of human brain lipids. Lipids 48:307-318. https ://doi.org/10.1007/s11745-013-3760-z

Amunts K, Zilles K (2015) Architectonic mapping of the human brain beyond Brodmann. Neuron 88:1086-1107. https://doi. org/10.1016/j.neuron.2015.12.001

Anderson DM, Spraggins JM, Rose KL, Schey KL (2015) High spatial resolution imaging mass spectrometry of human optic nerve lipids and proteins. J Am Soc Mass Spectrom 26:940-947. https://doi. org/10.1007/s13361-015-1143-9

Ataman B, Boulting GL, Harmin DA, Yang MG, Baker-Salisbury M, Yap EL, Malik AN, Mei K, Rubin AA, Spiegel I et al (2016) Evolution of Osteocrin as an activity-regulated factor in the primate brain. Nature 539:242-247. https://doi.org/10.1038/nature20111

Bauernfeind AL, Reyzer ML, Caprioli RM, Ely JJ, Babbitt CC, Wray GA, Hof PR, Sherwood CC (2015) High spatial resolution proteomic comparison of the brain in humans and chimpanzees. $\mathrm{J}$ Comp Neurol 523:2043-2061. https://doi.org/10.1002/cne.23777

Becker JS, Matusch A, Palm C, Salber D, Morton KA, Becker JS (2010) Bioimaging of metals in brain tissue by laser ablation inductively coupled plasma mass spectrometry (LA-ICP-MS) and metallomics. Metallomics 2:104-111. https://doi.org/10.1039/ b916722f

Becker JS, Matusch A, Wu B (2014) Bioimaging mass spectrometry of trace elements-recent advance and applications of LA-ICP-MS: a review. Anal Chim Acta 835:1-18. https://doi.org/10.1016/j. aca.2014.04.048

Beine B, Diehl HC, Meyer HE, Henkel C (2016) Tissue MALDI mass spectrometry imaging (MALDI MSI) of peptides. Methods Mol Biol 1394:129-150. https://doi. org/10.1007/978-1-4939-3341-9_10

Berry KA, Hankin JA, Barkley RM, Spraggins JM, Caprioli RM, Murphy RC (2011) MALDI imaging of lipid biochemistry in tissues by mass spectrometry. Chem Rev 111:6491-6512. https://doi. org/10.1021/cr200280p

Boaru SG, Merle U, Uerlings R, Zimmermann A, Weiskirchen S, Matusch A, Stremmel W, Weiskirchen R (2014) Simultaneous monitoring of cerebral metal accumulation in an experimental model of Wilson's disease by laser ablation inductively coupled plasma mass spectrometry. BMC Neurosci 15:98-2202-15-98. https://doi.org/10.1186/1471-2202-15-98

Bodzon-Kulakowska A, Antolak A, Drabik A, Marszalek-Grabska M, Kotlinska J, Suder P (2017) Brain lipidomic changes after morphine, cocaine and amphetamine administration-DESIMS imaging study. Biochim Biophys Acta 1862:686-691. S1388-1981(17)30063-X.

Bonilla E, Salazar E, Villasmil JJ, Villalobos R, Gonzalez M, Davila JO (1984) Copper distribution in the normal human brain. Neurochem Res 9:1543-1548

Bourassa MW, Miller LM (2012) Metal imaging in neurodegenerative diseases. Metallomics 4:721-738. https://doi.org/10.1039/c2mt2 $0052 \mathrm{j}$

Bozek K, Wei Y, Yan Z, Liu X, Xiong J, Sugimoto M, Tomita M, Paabo S, Sherwood CC, Hof PR et al (2015) Organization and evolution of brain lipidome revealed by large-scale analysis of human, chimpanzee, macaque, and mouse tissues. Neuron 85:695-702. https://doi.org/10.1016/j.neuron.2015.01.003

Brodmann K (1909) Vergleichende Lokalisationslehre der Grosshirnrinde in ihren Prinzipien dargestellt auf Grund des Zellenbaues, Barth, Leipzig. Translated by Laurence Garey as Localisation in the Cerebral Cortex (1994) Smith-Gordon, London. New edition 1999. Imperial College Press, London

Casagrande VA, Xu X (2004) Parallel visual pathways: a comparative perspective. In: Chalupa L, Werner JS (eds) The visual neurosciences. MIT Press, Cambridge, MA, USA, pp 494-506

Chan RB, Oliveira TG, Cortes EP, Honig LS, Duff KE, Small SA, Wenk MR, Shui G, Di Paolo G (2012) Comparative lipidomic analysis of mouse and human brain with Alzheimer disease. J Biol Chem 287:2678-2688. https://doi.org/10.1074/jbc. M111.274142

Cheng D, Jenner AM, Shui G, Cheong WF, Mitchell TW, Nealon JR, Kim WS, McCann H, Wenk MR, Halliday GM et al (2011) Lipid pathway alterations in Parkinson's disease primary visual cortex. PLoS One 6:e17299. https://doi.org/10.1371/journal.pone.00172 99

Chughtai K, Heeren RM (2010) Mass spectrometric imaging for biomedical tissue analysis. Chem Rev 110:3237-3277. https://doi. org/10.1021/cr100012c

Dekker TJ, Jones EA, Corver WE, van Zeijl RJ, Deelder AM, Tollenaar RA, Mesker WE, Morreau H, McDonnell LA (2015) Towards imaging metabolic pathways in tissues. Anal Bioanal Chem 407:2167-2176. https://doi.org/10.1007/s00216-014-8305-7

Dobrowolska J, Dehnhardt M, Matusch A, Zoriy M, Palomero-Gallagher N, Koscielniak P, Zilles K, Becker JS (2008) Quantitative imaging of zinc, copper and lead in three distinct regions of the human brain by laser ablation inductively coupled plasma mass spectrometry. Talanta 74:717-723. https://doi.org/10.1016/j.talan ta.2007.06.051

Eickhoff SB, Stephan KE, Mohlberg H, Grefkes C, Fink GR, Amunts K, Zilles K (2005) A new SPM toolbox for combining probabilistic cytoarchitectonic maps and functional imaging data. Neuroimage 25:1325-1335. https://doi.org/10.1016/j.neuroimage .2004 .12 .034

Eilam R, Aharoni R, Arnon R, Malach R (2016) Astrocyte morphology is confined by cortical functional boundaries in mammals ranging from mice to human. Elife. https://doi.org/10.7554/eLife.15915

Fahy E, Subramaniam S, Brown HA, Glass CK, Merrill AH Jr, Murphy RC, Raetz CR, Russell DW, Seyama Y, Shaw W et al (2005) A comprehensive classification system for lipids. J Lipid Res 46:839-861. https://doi.org/10.1194/jlr.E400004-JLR200

Fernandez R, Carriel V, Lage S, Garate J, Diez-Garcia J, Ochoa B, Castro B, Alaminos M, Fernandez JA (2016) Deciphering the lipid architecture of the rat sciatic nerve using imaging mass 
spectrometry. ACS Chem Neurosci 7:624-632. https://doi. org/10.1021/acschemneuro.6b00010

Gantz SC, Bean BP (2017) Cell-autonomous excitation of midbrain dopamine neurons by endocannabinoid-dependent lipid signaling. Neuron 93:1375-1387. https://doi.org/10.1016/j.neuro n.2017.02.025

Gessel MM, Norris JL, Caprioli RM (2014) MALDI imaging mass spectrometry: spatial molecular analysis to enable a new age of discovery. J Proteomics 107:71-82. https://doi.org/10.1016/j.jprot 2014.03.021

Glasser MF, Smith SM, Marcus DS, Andersson JL, Auerbach EJ, Behrens TE, Coalson TS, Harms MP, Jenkinson M, Moeller S et al (2016) The human connectome project's neuroimaging approach. Nat Neurosci 19:1175-1187. https://doi.org/10.1038/nn.4361

Guichardant M, Chen P, Liu M, Calzada C, Colas R, Vericel E, Lagarde M (2011) Functional lipidomics of oxidized products from polyunsaturated fatty acids. Chem Phys Lipids 164:544-548. https:// doi.org/10.1016/j.chemphyslip.2011.05.002

Heijs B, Carreira RJ, Tolner EA, de Ru AH, van den Maagdenberg AM, van Veelen PA, McDonnell LA (2015) Comprehensive analysis of the mouse brain proteome sampled in mass spectrometry imaging. Anal Chem 87:1867-1875. https://doi.org/10.1021/ac503952q

Hicks AM, DeLong CJ, Thomas MJ, Samuel M, Cui Z (2006) Unique molecular signatures of glycerophospholipid species in different rat tissues analyzed by tandem mass spectrometry. Biochim Biophys Acta 1761:1022-1029. S1388-1981(06)00157-0.

Higo N, Oishi T, Yamashita A, Matsuda K, Hayashi M (2002) Expression of MARCKS mRNA in lateral geniculate nucleus and visual cortex of normal and monocularly deprived macaque monkeys. Vis Neurosci 19:633-643. S0952523802195083

Higo N, Oishi T, Yamashita A, Murata Y, Matsuda K, Hayashi M (2004) Northern blot and in situ hybridization analyses for the development of myristoylated alanine-rich c-kinase substrate mRNA in the monkey cerebral cortex. Neuroscience 129:167177. S0306-4522(04)00660-8.

Hinds O, Polimeni JR, Rajendran N, Balasubramanian M, Amunts K, Zilles K, Schwartz EL, Fischl B, Triantafyllou C (2009) Locating the functional and anatomical boundaries of human primary visual cortex. Neuroimage 46:915-922. https://doi.org/10.1016/j.neuro image.2009.03.036

Holahan MR (2017) A shift from a pivotal to supporting role for the growth-associated protein (GAP-43) in the coordination of axonal structural and functional plasticity. Front Cellul Neurosci. https:// doi.org/10.3389/fncel.2017.00266

Horton JC, Hocking DR (1997) Myelin patterns in V1 and V2 of normal and monocularly enucleated monkeys. Cereb Cortex 7:166-177

Hubel DH, Wiesel TN (1977) Ferrier lecture. Functional architecture of macaque monkey visual cortex. Proc R Soc Lond B Biol Sci 198:1-59

Jackson SN, Wang HY, Woods AS (2005) Direct profiling of lipid distribution in brain tissue using MALDI-TOFMS. Anal Chem 77:4523-4527. https://doi.org/10.1021/ac050276v

Kedracka-Krok S, Swiderska B, Jankowska U, Skupien-Rabian B, Solich J, Dziedzicka-Wasylewska M (2016) Stathmin reduction and cytoskeleton rearrangement in rat nucleus accumbens in response to clozapine and risperidone treatment-comparative proteomic study. Neuroscience 316:63-81. https://doi. org/10.1016/j.neuroscience.2015.12.028

Kishimoto Y, Agranoff BW, Radin NS, Burton RM (1969) Comparison of the fatty acids of lipids of subcellular brain fractions. J Neurochem 16:397-404

Knauer B, Majka P, Watkins KJ, Taylor AWR, Malamanova D, Paul B, Yu HH, Bush AI, Hare DJ, Reser DH (2017) Whole-brain metallomic analysis of the common marmoset (Callithrix jacchus). Metallomics 9:411-423. https://doi.org/10.1039/c7mt00012j
Kompauer M, Heiles S, Spengler B (2017) Atmospheric pressure MALDI mass spectrometry imaging of tissues and cells at 1.4lateral resolution. Nat Methods 14:90-96. https://doi.org/10.1038/ nmeth.4071

Kropotova E, Klementiev B, Mosevitsky M (2013) BASP1 and its $\mathrm{N}$-end fragments (BNEMFs) dynamics in rat brain during development. Neurochem Res 38:1278-1284. https://doi.org/10.1007/ s11064-013-1035-y

Laux T, Fukami K, Thelen M, Golub T, Frey D, Caroni P (2000) GAP43, MARCKS, and CAP23 modulate PI(4,5)P(2) at plasmalemmal rafts, and regulate cell cortex actin dynamics through a common mechanism. J Cell Biol 149:1455-1472

Lazar AN, Bich C, Panchal M, Desbenoit N, Petit VW, Touboul D, Dauphinot L, Marquer C, Laprevote O, Brunelle A et al (2013) Time-of-flight secondary ion mass spectrometry (TOF-SIMS) imaging reveals cholesterol overload in the cerebral cortex of Alzheimer disease patients. Acta Neuropathol 125:133-144. https:// doi.org/10.1007/s00401-012-1041-1

Leu B, Koch E, Schmidt JT (2010) GAP43 phosphorylation is critical for growth and branching of retinotectal arbors in zebrafish. Dev Neurobiol 70:897-911. https://doi.org/10.1002/dneu.20829

Li Q, Bozek K, Xu C, Guo Y, Sun J, Paabo S, Sherwood CC, Hof PR, Ely JJ, Li Y et al (2017) Changes in lipidome composition during brain development in humans, chimpanzees, and macaque monkeys. Mol Biol Evol. https://doi.org/10.1093/ molbev/msx 065

Manuel I, Barreda-Gomez G, Gonzalez de San Roman E, Veloso A, Fernandez JA, Giralt MT, Rodriguez-Puertas R (2015) Neurotransmitter receptor localization: from autoradiography to imaging mass spectrometry. ACS Chem Neurosci 6:362-373. https ://doi.org/10.1021/cn500281t

Martel G, Uchida S, Hevi C, Chevere-Torres I, Fuentes I, Park YJ, Hafeez H, Yamagata H, Watanabe Y, Shumyatsky GP (2016) Genetic demonstration of a role for stathmin in adult hippocampal neurogenesis, spinogenesis, and NMDA receptor-dependent memory. J Neurosci 36:1185-1202. https://doi.org/10.1523/ JNEUROSCI.4541-14.2016

Martinez-Gardeazabal J, Gonzalez de San Roman E, Moreno-Rodriguez M, Llorente-Ovejero A, Manuel I, Rodriguez-Puertas $\mathrm{R}$ (2017) Lipid mapping of the rat brain for models of disease. Biochim Biophys Acta 1859(9 Pt B):1548-1557. https://doi. org/10.1016/j.bbamem.2017.02.011

Mathur BN, Caprioli RM, Deutch AY (2009) Proteomic analysis illuminates a novel structural definition of the claustrum and insula. Cereb Cortex 19:2372-2379. https://doi.org/10.1093/ cercor/bhn253

Matsumoto J, Sugiura Y, Yuki D, Hayasaka T, Goto-Inoue N, Zaima N, Kunii Y, Wada A, Yang Q, Nishiura K et al (2011) Abnormal phospholipids distribution in the prefrontal cortex from a patient with schizophrenia revealed by matrix-assisted laser desorption/ionization imaging mass spectrometry. Anal Bioanal Chem 400:1933-1943. https://doi.org/10.1007/s0021 6-011-4909-3

M-M P, Weiskirchen R, Gassler N, Bosserhoff AK, Becker JS (2013) Novel bioimaging techniques of metals by laser ablation inductively coupled plasma mass spectrometry for diagnosis of fibrotic and cirrhotic liver disorders. PLoS One 8:e58702. https://doi. org/10.1371/journal.pone.0058702

Mohammadi AS, Phan NT, Fletcher JS, Ewing AG (2016) Intact lipid imaging of mouse brain samples: MALDI, nanoparticle-laser desorption ionization, and $40 \mathrm{keV}$ argon cluster secondary ion mass spectrometry. Anal Bioanal Chem 408:6857-6868. https:// doi.org/10.1007/s00216-016-9812-5

Mueller C, Magaki S, Schrag M, Ghosh MC, Kirsch WM (2009) Iron regulatory protein 2 is involved in brain 
copper homeostasis. J Alzheimers Dis 18:201-210. https://doi. org/10.3233/JAD-2009-1136

Norris JL, Caprioli RM (2013) Analysis of tissue specimens by matrixassisted laser desorption/ionization imaging mass spectrometry in biological and clinical research. Chem Rev 113:2309-2342. https ://doi.org/10.1021/cr3004295

Nusbaum MP, Blitz DM, Marder E (2017) Functional consequences of neuropeptide and small-molecule co-transmission. Nat Rev Neurosci; 18(7):389-403

Owe SG, Erisir A, Heggelund P (2013) Terminals of the major thalamic input to visual cortex are devoid of synapsin proteins. Neuroscience 243:115-125. https://doi.org/10.1016/j.neuroscien ce.2013.03.031

Palomero-Gallagher N, Zilles K (2017) Cortical layers: Cyto-, myelo-, receptor- and synaptic architecture in human cortical areas. Neuroimage. S1053-8119(17):30682-30681

Portbury SD, Hare DJ, Sgambelloni C, Finkelstein DI, Adlard PA (2016) A time-course analysis of changes in cerebral metal levels following a controlled cortical impact. Metallomics 8:193-200. https://doi.org/10.1039/c5mt00234f

Preuss TM, Qi H, Kaas JH (1999) Distinctive compartmental organization of human primary visual cortex. Proc Natl Acad Sci USA 96:11601-11606

Ramos P, Santos A, Pinto NR, Mendes R, Magalhaes T, Almeida A (2014) Anatomical region differences and age-related changes in copper, zinc, and manganese levels in the human brain. Biol Trace Elem Res 161:190-201. https://doi.org/10.1007/s1201 1-014-0093-6

Remnestal J, Just D, Mitsios N, Fredolini C, Mulder J, Schwenk JM, Uhlen M, Kultima K, Ingelsson M, Kilander L et al (2016) CSF profiling of the human brain enriched proteome reveals associations of neuromodulin and neurogranin to Alzheimer's disease. Proteomics Clin Appl 10:1242-1253. https://doi.org/10.1002/ prca.201500150

Robichaud G, Garrard KP, Barry JA, Muddiman DC (2013) MSiReader: an open-source interface to view and analyze high resolving power MS imaging files on Matlab platform. J Am Soc Mass Spectrom 24:718-721. https://doi.org/10.1007/s1336 1-013-0607-z

Roh SE, Hong YH, Jang DC, Kim J, Kim SJ (2014) Lipid rafts serve as signaling platforms for mGlu1 receptor-mediated calcium signaling in association with caveolin. Mol Brain 7:9. https://doi. org/10.1186/1756-6606-7-9

Rosenke M, Weiner KS, Barnett MA, Zilles K, Amunts K, Goebel R, Grill-Spector K (2017) A cross-validated cytoarchitectonic atlas of the human ventral visual stream. Neuroimage. S1053-8119(17)30151-9

Schubert KO, Weiland F, Baune BT, Hoffmann P (2016) The use of MALDI-MSI in the investigation of psychiatric and neurodegenerative disorders: A review. Proteomics 16:1747-1758. https:// doi.org/10.1002/pmic.201500460

Shariatgorji M, Svenningsson P, Andren PE (2014) Mass spectrometry imaging, an emerging technology in neuropsychopharmacology. Neuropsychopharmacology 39:34-49. https://doi.org/10.1038/ npp. 2013.215

Skinner ER, Watt C, Besson JA, Best PV (1993) Differences in the fatty acid composition of the grey and white matter of different regions of the brains of patients with Alzheimer's disease and control subjects. Brain 116(Pt 3):717-725

Skraskova K, Khmelinskii A, Abdelmoula WM, De Munter S, Baes M, McDonnell L, Dijkstra J, Heeren RM (2015) Precise anatomic localization of accumulated lipids in Mfp2 deficient murine brains through automated registration of SIMS images to the Allen
Brain Atlas. J Am Soc Mass Spectrom 26:948-957. https://doi. org/10.1007/s13361-015-1146-6

Sugiura Y, Setou M (2009) Selective imaging of positively charged polar and nonpolar lipids by optimizing matrix solution composition. Rapid Commun Mass Spectrom 23:3269-3278. https://doi. org/10.1002/rcm.4242

Sugiura Y, Konishi Y, Zaima N, Kajihara S, Nakanishi H, Taguchi R, Setou M (2009) Visualization of the cell-selective distribution of PUFA-containing phosphatidylcholines in mouse brain by imaging mass spectrometry. J Lipid Res 50:1776-1788. https://doi. org/10.1194/jlr.M900047-JLR200

Susnea I, Weiskirchen R (2016) Trace metal imaging in diagnostic of hepatic metal disease. Mass Spectrom Rev 35:666-686. https:// doi.org/10.1002/mas.21454

Sussulini A, Becker JS, Becker JS (2017) Laser ablation ICP-MS: Application in biomedical research. Mass Spectrom Rev 36:4757. https://doi.org/10.1002/mas.21481

Uauy R, Hoffman DR, Peirano P, Birch DG, Birch EE (2001) Essential fatty acids in visual and brain development. Lipids 36:885-895

Van Lookeren Campagne M, Oestreicher AB, Van Bergen en Henegowen PM, Gispen WH (1989) Ultrastructural immunocytochemical localization of B-50/GAP43, a protein kinase C substrate, in isolated presynaptic nerve terminals and neuronal growth cones. J Neurocytol 18:479-489

Van Essen DC, Anderson CH, Felleman DJ (1992) Information processing in the primate visual system: an integrated systems perspective. Science 255:419-423

Van Meer G, Voelker DR, Feigenson GW (2008) Membrane lipids: where they are and how they behave. Nat Rev Mol Cell Biol 9:112-124. https://doi.org/10.1038/nrm2330

Van de Plas R, Yang J, Spraggins J, Caprioli RM (2015) Image fusion of mass spectrometry and microscopy: a multimodality paradigm for molecular tissue mapping. Nat Methods 12:366-372. https:// doi.org/10.1038/nmeth.3296

Veloso A, Astigarraga E, Barreda-Gomez G, Manuel I, Ferrer I, Giralt MT, Ochoa B, Fresnedo O, Rodriguez-Puertas R, Fernandez JA (2011a) Anatomical distribution of lipids in human brain cortex by imaging mass spectrometry. J Am Soc Mass Spectrom 22:329338. https://doi.org/10.1007/s13361-010-0024-5

Veloso A, Fernandez R, Astigarraga E, Barreda-Gomez G, Manuel I, Giralt MT, Ferrer I, Ochoa B, Rodriguez-Puertas R, Fernandez JA (2011b) Distribution of lipids in human brain. Anal Bioanal Chem 401:89-101. https://doi.org/10.1007/s00216-011-4882-x

Von Economo C, Koskinas GN (1925) Die Cytoarchitektonik der Hirnrinde des Erwachsenen Menschen: Textband und Atlas mit 112 Mikrophotographischen Tafeln. Springer, Vienna

Yuki D, Sugiura Y, Zaima N, Akatsu H, Hashizume Y, Yamamoto T, Fujiwara M, Sugiyama K, Setou M (2011) Hydroxylated and nonhydroxylated sulfatide are distinctly distributed in the human cerebral cortex. Neuroscience 193:44-53. https://doi.org/10.1016/j. neuroscience.2011.07.045

Zhao YY, Miao H, Cheng XL, Wei F (2015) Lipidomics: Novel insight into the biochemical mechanism of lipid metabolism and dysregulation-associated disease. Chem Biol Interact 240:220-238. https ://doi.org/10.1016/j.cbi.2015.09.005

Zilles K, Amunts K (2009) Receptor mapping: architecture of the human cerebral cortex. Curr Opin Neurol 22:331-339. https:// doi.org/10.1097/WCO.0b013e32832d95db

Zilles K, Amunts K (2010) Centenary of Brodmann's map-conception and fate. Nat Rev Neurosci 11:139-145. https://doi.org/10.1038/ $\operatorname{nrn} 2776$ 